\title{
Article \\ Synthesis and Characterization Superabsorbent Polymers Made of Starch, Acrylic Acid, Acrylamide, Poly(Vinyl Alcohol), 2-Hydroxyethyl Methacrylate, 2-Acrylamido-2-methylpropane Sulfonic Acid
}

\author{
Elżbieta Czarnecka ${ }^{1,2, *(\mathbb{D})}$ and Jacek Nowaczyk ${ }^{1}$ (D) \\ 1 Faculty of Chemistry, Nicolaus Copernicus University in Toruń, 7 Gagarina Street, 87-100 Torun, Poland; \\ jacek.nowaczyk@umk.pl \\ 2 Plastica Sp. z o.o., Frydrychowo 55, 87-410 Kowalewo Pomorskie, Poland \\ * Correspondence: elzbieta.czarnecka@tzmo-global.com
}

check for updates

Citation: Czarnecka, E.; Nowaczyk, J. Synthesis and Characterization Superabsorbent Polymers Made of Starch, Acrylic Acid, Acrylamide, Poly(Vinyl Alcohol), 2-Hydroxyethyl Methacrylate, 2-Acrylamido-2methylpropane Sulfonic Acid. Int. J. Mol. Sci. 2021, 22, 4325. https:// doi.org/10.3390/ijms22094325

Academic Editor: Raju Adhikari

Received: 8 March 2021

Accepted: 19 April 2021

Published: 21 April 2021

Publisher's Note: MDPI stays neutral with regard to jurisdictional claims in published maps and institutional affiliations.

Copyright: (c) 2021 by the authors. Licensee MDPI, Basel, Switzerland. This article is an open access article distributed under the terms and conditions of the Creative Commons Attribution (CC BY) license (https:// creativecommons.org/licenses/by/ $4.0 /)$.

\begin{abstract}
Three polymers with excellent absorption properties were synthesized by graft polymerization: soluble starch-g-poly(acrylic acid-co-2-hydroxyethyl methacrylate), poly(vinyl alcohol)/potato starch-g-poly(acrylic acid-co-acrylamide), poly(vinyl alcohol)/potato starch-g-poly(acrylic acid-coacrylamide-co-2-acrylamido-2-methylpropane sulfonic acid). Ammonium persulfate and potassium persulfate were used as initiators, while $N, N^{\prime}$-methylenebisacrylamide was used as the crosslinking agent. The molecular structure of potato and soluble starch grafted by synthetic polymers was characterized by means of Fourier Transform Infrared Spectroscopy (FTIR). The morphology of the resulting materials was studied using a scanning electron microscope (SEM). Thermal stability was tested by thermogravimetric measurements. The absorption properties of the obtained biopolymers were tested in deionized water, sodium chroma solutions of various concentrations and in buffer solutions of various $\mathrm{pH}$.
\end{abstract}

Keywords: semi-interpenetrating network hydrogel; biomaterial; superabsorbent polymer; hydrogel; graft copolymerization

\section{Introduction}

In 1976, the United States Department of Agriculture introduced polymers with water absorbency called superabsorbent polymers (SAPs) [1], which have found wide application in many industries including: gardening, agriculture, cosmetics, controlled drug release, hygiene products, and wastewater treatment [2,3]. These extraordinary polymer materials consist of weakly cross-linked chains having hydrophilic moieties, allowing them to retain water up to thousands of times their own weight [4]. Most of the SAPs industrially available are produced from synthetic polymers, mostly by the copolymerization of vinyl monomers specifically including acrylic or methacrylic acid derivatives [3]. Therefore, the market of SAPs is dominated by petroleum-based synthetic polymers having a long decomposition time, which inflicts a negative impact on the environment [5].

The vast majority of SAPs produced recently are used in disposable products and subsequently dumped in landfills or utilized by incineration; in both cases they are not safe for ecosystems [6]. Nowadays, many people care about their own physical and mental health, thus they become increasingly aware of environmental protection and the diversified development of natural resources. Consequently, the industry tends to deliver more ecological and biodegradable products in order to fulfill consumers' expectations. The increasing interest in the polysaccharides as an excellent renewable raw material fits this trend. Polysaccharides have more advantages; they are cheap, nontoxic biodegradable, and easy to modify. However, in the field of SAPs polysaccharides did not meet the requirements in terms of absorption and mechanical properties [7]. For this reason, a lot of 
research effort had been employed both in academic and industrial institutions to solve the problem [8].

There has been a lot of research on the chemical modification and cross-linking of cellulose. However, starch modification was also tested with various synthetic monomers, e.g., acrylic acid [9-15], acrylamide [16-18], methacrylamide [19,20], acrylonitrile [21], vinyl alcohol [22], 2-acrylamido-2-methylpropanesulfonic acid [23,24], styrene [25], vinylimidazole [26].

Starch is a very popular source material for the production of biodegradable goods and for years was an important subject of research [27]. It is the second most abundant natural carbohydrate with many advantages including low price, nontoxicity, ease of chemical modification and processability. Obtained from renewable sources such as potato, corn, wheat and rice and capable of being processed in water-based solvents, starch is definitely a green material considered as a potential alternative to some petroleum-based polymers [28]. Morphologically, starch consists of nearly spherical granules of diameter between 1 and $150 \mu \mathrm{m}$. Chemically, it is composed of two similar polysaccharidesamylose and amylopectinboth - built of glucose rings connected by $\alpha$-glycoside bonds. The former forms mostly linear chains composed of $\alpha$-D-(1-4) glucan units. In contrast, amylopectin is a highly branched version of $\alpha$-D-(1-4) glucan chains linked together with $\alpha$-D-(1-6) glycosidic linkages at branch points. Starch is completely soluble in water above $130^{\circ}$ and in alkali solutions at lower temperatures. The rapid cooling of concentrated starch solutions results in formation of hydrogel, while slow cooling of dilute solutions can lead to crystallization of amylose components. Long amylose chains as well as long amylopectin branches can crystallize, adopting helical conformation with hydrophilic core and helix twist formed of about six glucose units. Strong hydrogen bonding between glucose $\mathrm{OH}$ groups from neighboring chains or chain segments prevents the polymer from easy swelling and dissolution. Dry starch granules absorb little water, retaining their initial crystallinity and hydrogen bonding structure. It requires significantly elevated temperature to loosen the compact basic structure and let the solvent inside granules. Therefore, starch gelation occurs in high temperatures when the interchain forces are weakened enough to allow water molecules to penetrate the interchain space. As a result, nonmodified starch cannot be used as an efficient water absorbent.

Despite the abovementioned drawbacks, starch still remains in the hot-spot of scientific interest as a promising biodegradable absorbent polymer. The main reason is the ease of the chemical modification of starch, allowing researchers to tailor its properties according to specific needs. In the case of superabsorbents, the polymer is expected to easily absorb high amounts of water and water-based solutions at room temperature. Other requirements are the preservation of a shape-in other words, a polymer cannot dissolve in the solvent releasing fluids. To change starch into such a material it is necessary to modify its chemical structure to facilitate the penetration of the interchain space by the water molecules. Polysaccharides are modified in this direction by grafting hydrophobic side-chains to the carbohydrate main chain. The technique has been extensively studied in the case of cellulose [29]; however, recently one can also find numerous studies of starch modification [30]. Another approach employs the formation of an interpenetrating network (IPN) of starch and nonionic or ionic hydrogel [31]. Recently semi-interpenetrating network hydrogels (SIPNH) are often studied as a combination of both previous approaches [32]. 
In the present study, we investigated the synthesis and usefulness of the modification of starch in order to obtain a semi-interpenetrating network hydrogel utilizing graft copolymerization of acrylic acid (AA), 2-hydroxyethyl methacrylate (HEMA), acrylamide (AM), and/or 2-acrylamido-2-methylpropane sulfonic acid (AMPS) for starch backbones. Additionally, we studied the effect of poly(vinyl alcohol) (PVA) addition. The polymerization of acrylic acid [33] and acrylamide [34] leads to formation of hydrophilic chains, improving the water absorption properties of the system [35]. Linear poly(vinyl alcohol) possesses a flexible structure, excellent permeability of fluids, and low interfacial tension $[36,37]$ due to the presence of the hydroxyl pendant groups. PVA has many advantages, such as including good swelling capacity and nontoxicity; however, it forms unstable hydrogels because their structure is maintained by weak hydrogen bonds [38]. Nevertheless, PVA was found to be a good additive to other, more stable hydrogels, improving their sorption effectiveness. Typically, adding PVA to other water swollen polymers led to the formation of IPN hydrogel.

In the present study, we have achieved the synthesis and characterization of the three starch-based superabsorbents schematically depicted in Figure 1. The schemes presented represent possible reaction products based on the literature. One is a crosslinked graft copolymer of starch modified with AA and HEMA (Figure 1A). The second comonomer was used to increase the hydrophilicity of the resulting network [20]. The other two schemes are of SIPNH type superabsorbent materials with graft-modified starch as the main component and PVA as a linear hydrophilic counterpart. Similar studies have already been published but mostly in the context of the synthesis route. In our study, we have undertaken the effort to investigate and compare three different gel systems. Although the methods of starch modification with acrylic monomers are known in the literature, the products usually suffer from poor sorption abilities and water retention. Addressing this issue, we have chosen an original combination of monomers and compared three different structural modes. For the sake of comparison, the simple and widely published starch-gpoly(acrylic acid-co-2-hydroxyethyl methacrylate) was synthesized and subjected to similar tests. In our study SS and PS starch were modified by the combination of the following monomers: AA and AM (Figure 1B); AA, AM and AMPS in the second case (Figure 1C). The AMPS was used to introduce a large number of ionizable groups $-\mathrm{COO}^{-}$and $-\mathrm{SO}_{3}{ }^{-}$, which can increase the swelling capacity [39]. The presence of different comonomers in the polymer chain provides different hydrophobicity, leading to a $\mathrm{pH}$-sensitive material [40]. 
A

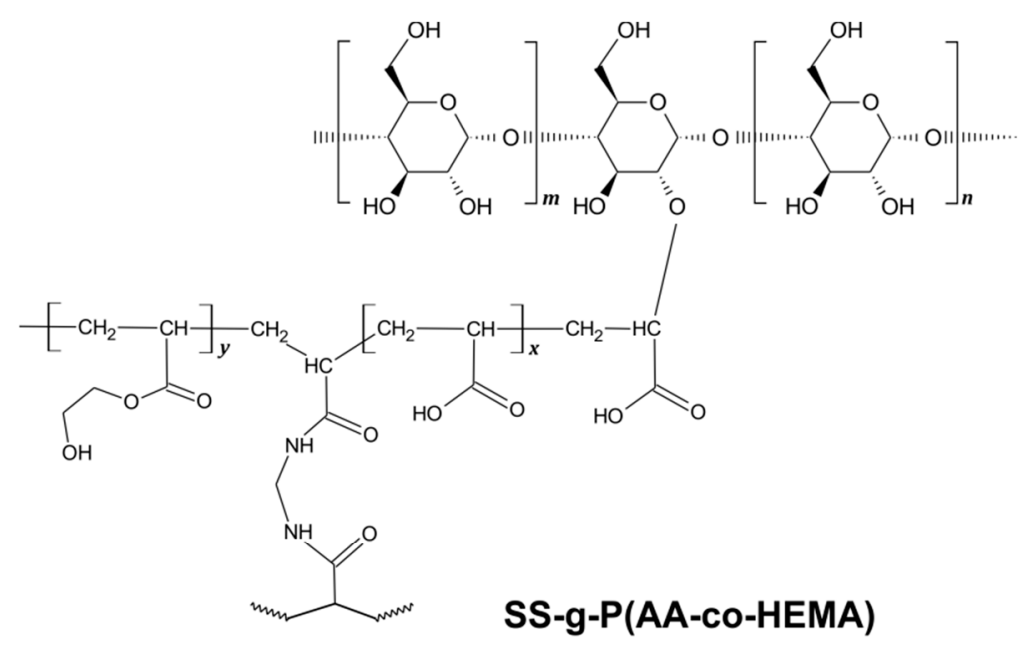

B<smiles>CCC(CC)C(=O)NCNC(=O)C(CCCCC(=O)O)CCC(CC(C)(C)C)C(=O)O</smiles>

C

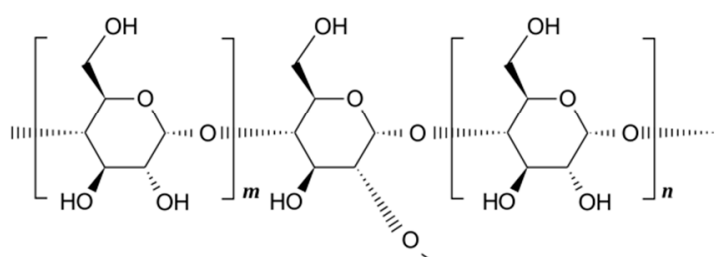<smiles>CCC(CC(C)C)C(=O)NC(C)(C)S(=O)(=O)O</smiles><smiles>CCCCCC(CC)C(=O)NCNC(=O)C(CC)CC</smiles>

PS-g-P(AA-Co-AM-Co-AMPS)

Figure 1. Schematic representation of synthesized grafted starch counterparts of superabsorbent polymers: soluble starch-g-poly(acrylic acid-co-2-hydroxyethylmethacrylate) SS-g-P(AA-co-HEMA) (A), potato starch-g-poly(acrylic acid-co-acrylamide) PS-g-P(AA-co-AM) (B), and poly(vinyl alcohol)/potato starch-g-poly(acrylic acid-co-acrylamide-co-2-acrylamido-2-methylpropane sulfonic acid) PS-g-P(AA-co-AM-co-AMPS) (C). 


\section{Experimental Methods}

\subsection{Materials}

In the recent work we have used polymer substrates such as potato starch (PS) ACS reagent grade (Sigma Aldrich, Poznań, Poland), soluble starch (SS) pure (Sigma Aldrich, Poznań, Poland), and poly(vinyl alcohol) (PVA) pure (Sigma Aldrich, Poznań, Poland). We have used acrylic acid (AA) pure (Sigma Aldrich, Poznań, Poland); 2-hydroxyethyl methacrylate (HEMA) pure (Sigma Aldrich, Poznań, Poland), and 2-acrylamido-2-methylpropane sulfonic acid (AMPS) pure (Sigma Aldrich, Poznań, Poland) as grafting monomers. Potassium persulfate (KPS) analytical grade (Sigma Aldrich, Poznań, Poland) was used as the reaction initiator. $N, N^{\prime}$-methylenebisacrylamide (MBA) pure (Sigma Aldrich, Poznań, Poland) was applied as crosslinking reagent. Besides, we have also used other auxiliary reagents such as sodium hydroxide $(\mathrm{NaOH})$ (Sigma Aldrich, Poznań, Poland); nitrogen gas $\left(\mathrm{N}_{2}\right)$ technical grade; ethanol 96 vol\% (Bioetanol AEG Ltd., Chełmża, Poland). All these compounds were used as obtained. Necessary solutions were prepared using deionized water.

\subsection{Infrared Spectroscopy}

The identification of reaction products was conducted by means of Fourier transform infrared spectroscopy (FTIR). Dry pot material was analyzed at room temperature in horizontal attenuated total reflectance (ATR) mode with a diamond crystal. FTIR spectra in the range between 4000 and $400 \mathrm{~cm}^{-1}$ were collected using a Bruker Vertex $70 \mathrm{~V}$ spectrometer (Bruker Optoc $\mathrm{GmbH}$, Ettlingen, Germany). For each sample for 16 scans with a resolution of $4 \mathrm{~cm}^{-1}$ was recorded and averaged using built-in machine routine. The resulting spectra have been normalized analyzed using OPUS 7.5 software (Bruker Optoc $\mathrm{GmbH}$, Ettlingen, Germany).

\subsection{Thermal Analysis}

Thermal properties of materials were analyzed using a Simultaneous TGA-DTA thermal-analyzer type SDT 2960 Simultaneous TGA-DTA from TA Instruments, Champaign, IL, USA) at temperatures ranging from $20^{\circ} \mathrm{C}$ to $1000{ }^{\circ} \mathrm{C}$. For all studied samples of ca. 2-4 mg a heating rate of $10^{\circ} \mathrm{C} / \mathrm{min}$ was applied and tests were carried out under atmospheric air. The device was specified with a dynamic temperature precision within the limits of $\pm 0.5^{\circ} \mathrm{C}$ and a calorimetric accuracy/precision of $\pm 2 \%$ (based on metal standards). Recorded thermograms were analyzed using TA Universal Analysis Software. The analysis was employed to investigate a pristine polymer as well as a polymer after 10 cycles of swelling/drying.

\subsection{Scanning Electron Microscopy}

Surface topography and size of superabsorbent particles were tested using a scanning electron microscope manufactured by LEO Electron Microscopy Ltd. Cambridge, UK, model $1430 \mathrm{VP}$. The sample was tested as dry granules (not milled) with gold coating. The apparatus was working in SE mode under the following conditions: accelerating voltage $10 \mathrm{kV}$, working distance about $11 \mathrm{~mm}$ (exact WD values are given in the figures). The surface of the granules was analyzed at three sites. The test samples were dried immediately before the analysis under vacuum at the temperature of $50.0^{\circ} \mathrm{C} \pm 0.1{ }^{\circ} \mathrm{C}$ for $24 \mathrm{~h}$. Scanning electron microscopy was used to determine the shape, size, and morphology of superabsorbent polymers.

\subsection{Preparation of Soluble Starch-G-Poly(Acrylic Acid-Co-2-Hydroxyethylmethacrylate)}

We mixed $2.0149 \mathrm{~g}$ of soluble starch and $35 \mathrm{~mL}$ of deionized water in a $250 \mathrm{~mL}$ round bottomed flask. The system was heated to $80^{\circ} \mathrm{C}$ by the heating mantle and stirred with a mechanical stirrer at a speed of $195 \mathrm{rpm}$ for $30 \mathrm{~min}$. Once the starch was gelatinized, the flask with its contents was transferred to a water bath and a nitrogen inlet was mounted. The temperature was adjusted to $60^{\circ} \mathrm{C}$, and then $0.092 \mathrm{~g} / \mathrm{mol} \mathrm{KPS}$ solution was added. 
After $15 \mathrm{~min}$, a mixture of monomers containing $1.512 \mathrm{~g}$ AA and $1.514 \mathrm{~g}$ HEMA was added to the continuously stirred mixture. After another $15 \mathrm{~min}$ crosslinker was introduced to the mixture $(0.067 \mathrm{~g} / \mathrm{mol} \mathrm{MBA})$. The flask content was stirred for $3 \mathrm{~h}$ under a nitrogen atmosphere using a mechanical stirrer at the temperature of $60^{\circ} \mathrm{C}$. Afterwards the system was cooled to room temperature and the mixture $\mathrm{pH}$ was adjusted to 9.5 with solution of $\mathrm{NaHCO}_{3} 0.5 \mathrm{~g} / \mathrm{mol}$ and $10 \mathrm{wt} \% \mathrm{NaOH}$ solution. The resulting gel was washed thoroughly with ethanol, which was filtered off after $4 \mathrm{~h}$. The product was dried in a vacuum oven for $48 \mathrm{~h}$ at $50{ }^{\circ} \mathrm{C}$. After drying, the obtained product was ground in a laboratory mill (IKA A-10) and stored in a desiccator, away from moisture, light, and heat. The synthesis mechanism scheme is given in Figure 2, showing subsequent stages of the process. This mechanism is similar in all cases studied here.

1. free radical generation from initiatior

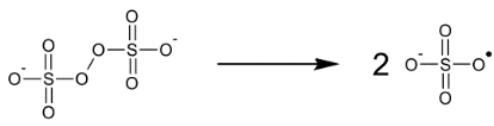

2. activation of starch main chain<smiles>CO[C@H]1C(CO)O[C@@H](OC)[C@@H](O)C1O</smiles>

3. initiation of grafting<smiles>[R]C(=O)C=C[CH]O[C@H]1[C@@H](OC)[C@@H](OC)[C@@H](CO)O[C@H]1OC</smiles>

4. graft chain propagation

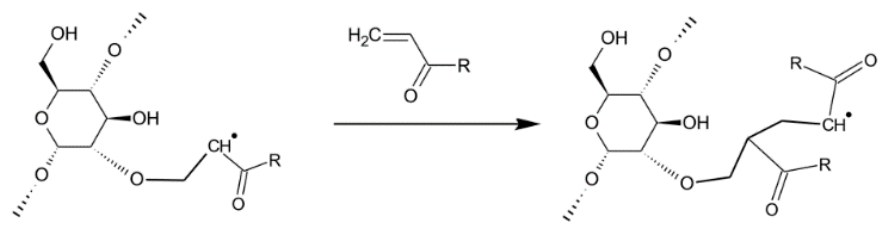

5. crosslinking of the grafts

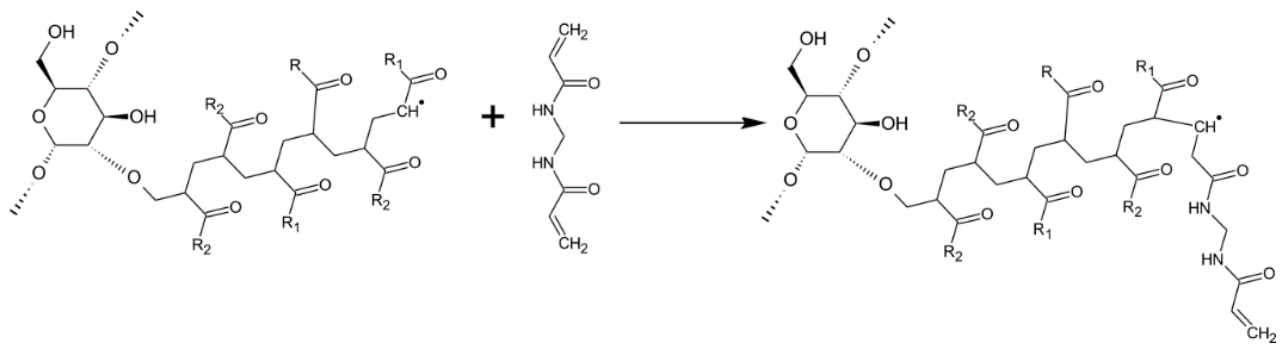

Figure 2. Possible mechanism of the grafting/crosslinking reaction of starch, acrylate monomers and MBA crosslinker. 


\subsection{Preparation of Poly(Vinyl Alcohol)/Potato Starch-G-Poly(Acrylic Acid-Co-Acrylamide)}

A three-necked round-bottom flask $250 \mathrm{~mL}$ was filled with $3.020 \mathrm{~g}$ of potato starch, $18 \mathrm{~mL}$ of distilled water and $0.9 \mathrm{~mL}$, of $40 \mathrm{wt} \% \mathrm{NaOH}$ solution. The flask was placed in a water bath at the temperature of $40{ }^{\circ} \mathrm{C}$ under a nitrogen atmosphere and stirred with a mechanical stirrer. When the starch was gelatinized, to the mixture was added: $10 \mathrm{~mL}$ of $2.817 \mathrm{~g} / \mathrm{mol} \mathrm{AM}$ solution and $17.992 \mathrm{~g}$ AA neutralized with $\mathrm{NaOH}$ solution. After $30 \mathrm{~min}$, the temperature was raised to $50^{\circ} \mathrm{C}$ and $0.015 \mathrm{~g}$ of KPS was added as initiator and 15 min later $20 \mathrm{~mL}$ of PVA aqueous solution (2006 g PVA) was added. The mixture was stirred for $30 \mathrm{~min}$ and a solution of crosslinking agent $(0.068 \mathrm{~g} / \mathrm{mol} \mathrm{MBA})$ was introduced. Afterwards the mixture turned into a thick gel and was stirred for $4 \mathrm{~h}$ using a mechanical stirrer. The obtained product was removed from the flask and cut into pieces $5 \times 5 \mathrm{~mm}$. The pieces were dried for $120 \mathrm{~h}$ at ambient temperature, and then transferred to a vacuum oven at $50{ }^{\circ} \mathrm{C}$ for $24 \mathrm{~h}$. After drying, it was ground into small pieces in an IKA A-10 basic laboratory mill. The mechanism of semi-interpenetrating network hydrogel formation according to this synthesis is schematically depicted in Figure 3.

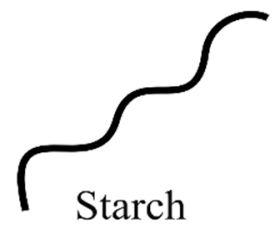

Starch

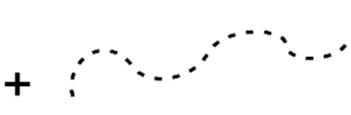

Poly(vinyl alcohol)

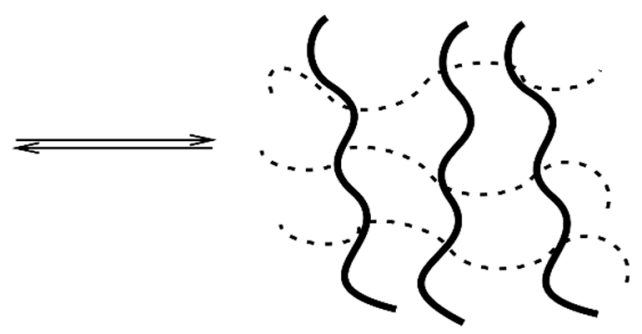

starch / PVA solution<smiles>CCC(C)CC(CC(C)C)CC(CC)CC(C)C</smiles>

acrylic monomer
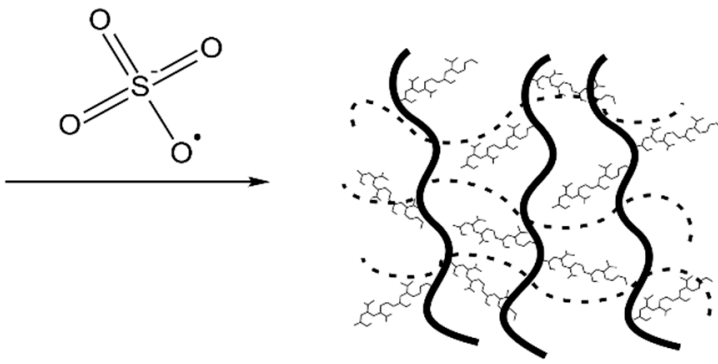

grafted starch / PVA solution

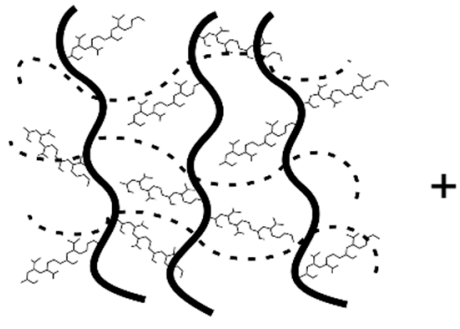

acrylic monomer<smiles>[CH2+][C@H](CC)C(=O)CC</smiles><smiles>O=S(=O)([O-])[O-]</smiles>

MBA

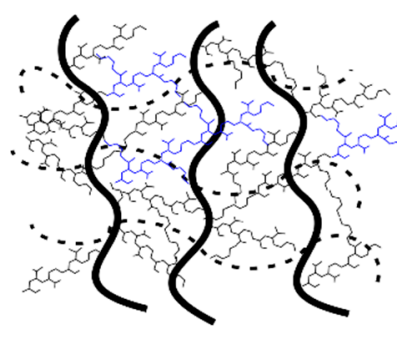

starch/PVA semi-interpenetrating hydrogel

Figure 3. Possible mechanism of a semi-interpenetrating network hydrogel formation from crosslinked starch and linear PVA. 


\subsection{Preparation of Poly(Vinyl Alcohol)/Potato Starch-G-Poly(Acrylic}

Acid-Co-Acrylamide-Co-2-Acrylamido-2-Methylpropane Sulfonic Acid)

Firstly, a solution consisting of $1.0631 \mathrm{~g}$ PVA dissolved in $50 \mathrm{~mL}$ of deionized water was poured into a three-necked, round bottomed flask. Then, $1.0764 \mathrm{~g}$ of potato starch, pregelatinized in $50 \mathrm{~mL}$ of deionized water was added and the mixture was stirred using a mechanical stirrer under nitrogen atmosphere at $60^{\circ} \mathrm{C}$. After about $30 \mathrm{~min}, 0.343 \mathrm{~g} / \mathrm{mol}$ KPS solution was added and during $15 \mathrm{~min}$, the temperature was decreased to $40^{\circ} \mathrm{C}$. Then, we poured $30 \mathrm{~mL}$ of monomer solution containing $3.339 \mathrm{~g} \mathrm{~A}, 3.600 \mathrm{~g} \mathrm{AM}$ and $3.600 \mathrm{~g}$ AMPS into the mixture and stirred it. Finally, a solution of crosslinker $1.503 \mathrm{~g} / \mathrm{mol}$ of MBA was added. The content of the flask was alkalinized to $\mathrm{pH} 11$ using $\mathrm{NaOH}$ solution. The mixture was kept for $3 \mathrm{~h}$ at $70{ }^{\circ} \mathrm{C}$ to complete the reaction. The product obtained was washed with $80 \mathrm{vol} \%$ ethanol and dried in a vacuum oven at $50{ }^{\circ} \mathrm{C}$ for $48 \mathrm{~h}$. After drying, it was ground into small pieces in an IKA A-10 basic laboratory mill.

\subsection{Swelling Characteristics}

The swelling characteristics including properties such as degree of swelling $\left(\mathrm{Q}_{\mathrm{t}}\right)$, equilibrium swelling $\left(Q_{e q}\right)$ and swelling rate, have been determined for starch and all new SAP materials. To determine the equilibrium swelling, expressing maximal mass of water per $1 \mathrm{~g}$ of superabsorbent, about $0.1000 \mathrm{~g}$ of dried polymer sample was dispersed in double distilled water to swell for $24 \mathrm{~h}$. After filtration, the extracted gel was reweighed and $\mathrm{Q}_{\mathrm{eq}}$ was calculated using following formula:

$$
\mathrm{Q}_{\mathrm{eq}}=\frac{\mathrm{w}_{\mathrm{s}}-\mathrm{w}_{\mathrm{d}}}{\mathrm{w}_{\mathrm{d}}}
$$

where $\mathrm{w}_{\mathrm{d}}$ and $\mathrm{w}_{\mathrm{s}}$ are the weights $[\mathrm{g}]$ of the dry sample and water swollen sample, respectively.

The degree of swelling was determined in the similar way but the sample was removed from the solvent (water, $\mathrm{NaCl}$ soln., or buffer) at certain time dried form the excess of surface water weighted and then returned to the solvent. The degree of swelling (also referred to as water absorbency) was determined using following formula:

$$
\mathrm{Q}_{\mathrm{t}}=\frac{\mathrm{w}_{\mathrm{t}}-\mathrm{w}_{\mathrm{d}}}{\mathrm{w}_{\mathrm{d}}}
$$

where $\mathrm{w}_{\mathrm{t}}$ is the weights $[\mathrm{g}]$ of the swollen sample at a given time. The $\mathrm{pH}$-dependent swelling experiments were carried out by immersing about $0.1000 \mathrm{~g}$ of dried superabsorbent in solutions with a defined $\mathrm{pH}$ at $25^{\circ} \mathrm{C}$ for $24 \mathrm{~h}$. Defined $\mathrm{pH}$ buffer solutions were prepared from $0.1 \mathrm{M} \mathrm{HCl}$ and $0.1 \mathrm{M} \mathrm{NaOH}$ solution (controlled by a $\mathrm{pH}$ meter by ChemLand, model 7011-01. Weight of swollen samples was measured after surface drying with filter paper. We used $1 \mathrm{wt} \%, 2 \mathrm{wt} \%, 4 \mathrm{wt} \%$ and $8 \mathrm{wt} \%$. NaCl solutions were $\mathrm{t}$ test the ionic strength on the samples.

\subsection{Swelling Dynamics}

The swelling properties of superabsorbent hydrogels, such as water absorption and fluid retention, were studied according to common methods described in the literature [41]. The absorbency rate of the studied absorbents was measured for ground particle samples of approximately $0.100 \pm 0.001 \mathrm{~g}$. Dry absorbent powder was inserted into weighted teabags and then dipped in $250 \mathrm{~mL}$ of distilled water. The kinetics of swelling is complex process, which is usually described mathematically using empirical models. Description of this process is often narrowed to investigation of initial swelling rate, i.e., when the swelling is significantly below $60 \%$. Initial swelling rate is determined from the formula derived from Voigt viscoelasticity model combining a spring with dashpot. The equation allows us to 
manage a fast transition from a high initial rate toward a very slow rate near the end of the process [12]. Using this approach, one comes to following equation:

$$
\mathrm{Q}_{\mathrm{t}}=\mathrm{Q}_{\mathrm{eq}}\left(1-\exp \left(-\frac{\mathrm{t}}{\tau}\right)\right)
$$

where $\tau$ is so-called "rate parameter", which in the original Voigt model is referred to as the "retardation time" and as such determines the influence of the dashpot.

There are a number of factors that may influence the swelling characteristics and kinetics in particular. Among the most notable are $\mathrm{pH}$, temperature, solvent properties, and structural parameters of polymer network. In this work we have found that the $Q_{t}=f(t)$ plot can be described using simple power law equation in the following form:

$$
\mathrm{Q}_{\mathrm{t}}=\mathrm{A} \cdot \exp \left(-\mathrm{b} \cdot \mathrm{t}^{-\frac{1}{2}}\right)
$$

where $A$ and $b$ are empirical coefficients. However, detailed analysis revealed that these parameters could be given specific phenomenological explanation. Thus, A is an estimate of the equilibrium swelling $\left(\mathrm{Q}_{\mathrm{eq}}\right)$ while $\mathrm{b}$ corresponds with the diffusion rate of the solvent in polymer interchain spaces. The model accuracy is expressed by $\mathrm{R}^{2}$ and Fit Standard Error (FSE) provided in tables together with equation coefficients.

\section{Results and Discussion}

\subsection{Analysis of the Synthesis Mechanism}

Various types of monomers, such as AA, AM, AMPS, and HEMA, have been used in a homogeneous medium to graft starch backbone. The reaction was initiated by KPS and the graft chains were crosslinked using MBA. The reaction mechanism is visualized in Figures 2 and 3, indicating the most important reaction stages and the phenomenology of the IPN formation. Initially, the thermal dissociation of KPS results in the formation of sulfate radical anion, which is assumed to extract the hydrogen atom from the hydroxyl group of starch's glucose unit at position two or three, which forms a radical. The monomer molecules close to the macroradical sites scavenge the unpaired electron attaching to polysaccharide backbone. This mechanism of initiation is fundamentally different from the oxidative radical initiation by $\mathrm{Ce}^{4+}$ ions, which form radical sites by the cleavage of the $\mathrm{C} 2-\mathrm{C} 3$ bond of the glucose unit. The influence of initiation on the structure and properties of the resulting hydrogel was discussed in our previous paper [12]. Since the monomer attached to glucose unit has a radical site it starts the chain growth process according to propagation reaction of chain polymerization. The monomers employed in the graft chain's formation possess ionophore groups, thus, the resulting network is rich in hydrophilic, ionizable groups such as anionic $-\mathrm{COO}^{-},-\mathrm{SO}_{3}{ }^{-}$, and cationic- ${ }^{+} \mathrm{NH}_{2}$-improving aqueous liquids' absorption. The use of inert monomers (acrylamide, 2-hydroxyethyl methacrylate) may facilitate the control of swelling, and sensitivity to $\mathrm{pH}$ of the environment. The system PVA/PS-g-P(AA-co-AM) is formed by partially interpenetrating polymer networks schematically depicted in Figure 3. The linear PVA polymer chains penetrate the 3D network of amylase and amylopectin, which undergo grafting. Grafted and crosslinked starch introduce chemically crosslinked polymer network that is additionally physically crosslinked by hydrogen bonding with PVA. This kind of interaction between the chains improves the stability of the hydrogel in a highly swollen state. On the other hand, the presence of PVA increases the swelling capacity of the system.

\subsection{FTIR Analysis}

The superabsorbent polymers obtained during this study are based on starch and acrylic acid, to which additional monomers have been added (AM, HEMA, AMPS). The authors analyzed the FTIR spectra of the products and main reagents (collected in Figure 4) based on the recent literature data and IR spectra interpretation handbooks [42]. From the obtained results one can notice that there are no noticeable differences between potato starch 
(PS) and soluble starch (SS), which was already discussed in the literature [12]. Both kinds of starch have spectra that show the same characteristic peaks and similar signal patterns. The peaks at 3300 and $2900 \mathrm{~cm}^{-1}$ are due to $\mathrm{OH}$ bonds and $\mathrm{CH}_{2}$ deformation, respectively [43]. The peaks at $1650 \mathrm{~cm}^{-1}$ can be assigned to flexing vibrations of water molecules absorbed in the amorphous regions of starch. The wavelength for about $1410 \mathrm{~cm}^{-1}$ is characteristic for the bending vibrations of $\mathrm{C}-\mathrm{H}$ bonds in methyl groups, while the band about $1140 \mathrm{~cm}^{-1}$ indicates the presence of glycosidic $\mathrm{C}-\mathrm{O}-\mathrm{C}$ bonds. The peaks at about $1070 \mathrm{~cm}^{-1}$ and $1000 \mathrm{~cm}^{-1}$ can be assigned to starch crystalline and amorphous regions, respectively. The binding at about $930 \mathrm{~cm}^{-1}$ was attributed to the skeletal oscillation of the $\alpha 1-4$ backbone linkages. The peak found at $760 \mathrm{~cm}^{-1}$ was assigned to the stretching of $\mathrm{C}-\mathrm{C}$ bonds and the one at about $570 \mathrm{~cm}^{-1}$ was assigned to the skeletal vibration of the pyranose ring. All spectra with designated characteristic peaks are present in the Supplementary Materials.

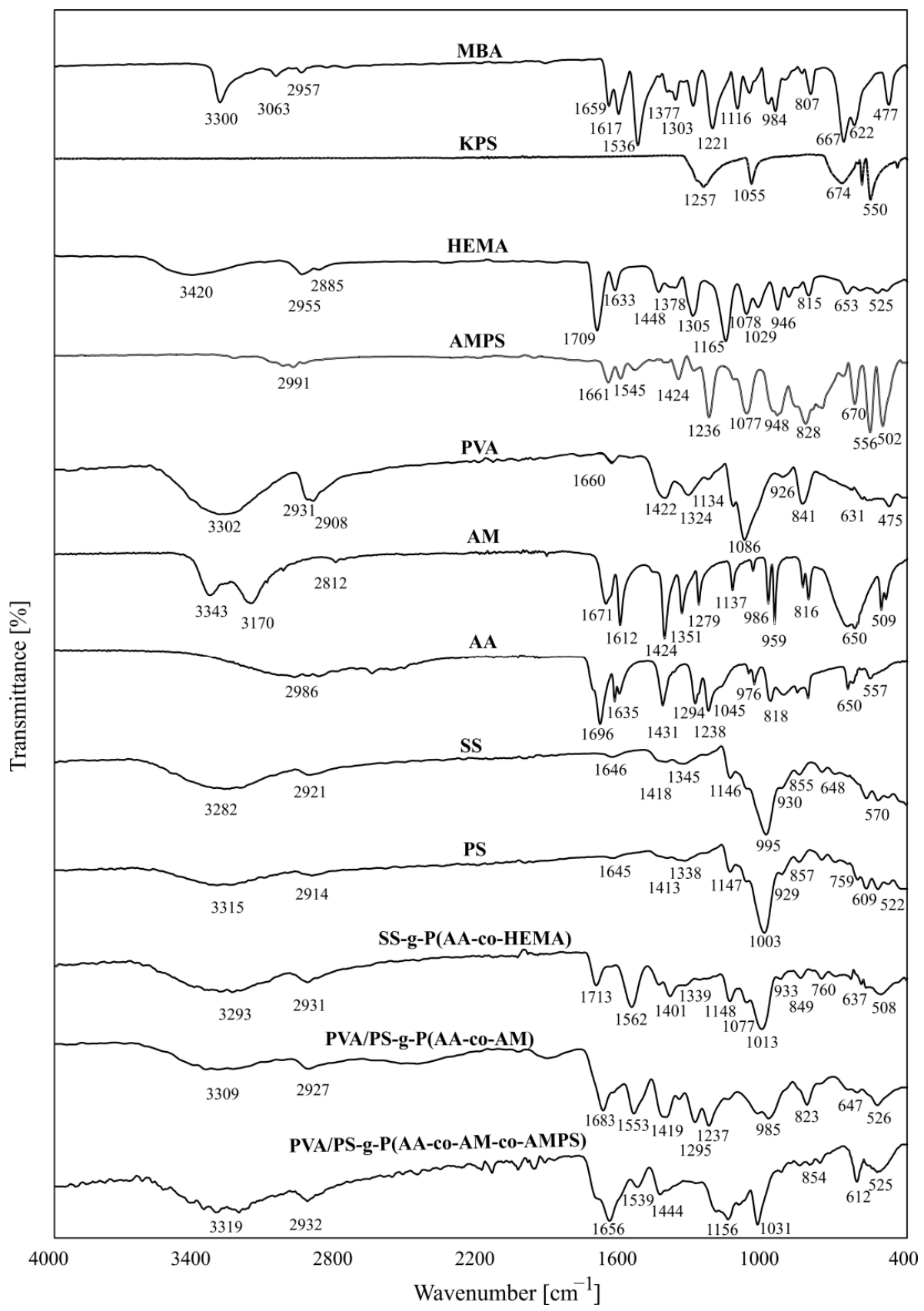

Figure 4. FTIR spectra of AMPS, PVA, AA, MBA KPS, PS, AM, PVA/PS-g-P(AA-co-AM-co-AMPS), PVA/PS-g-P(AA-co-AM) and SS-g-P(AA-co-HEMA). 
The spectrum of the superabsorbent network SS-g-P(AA-Co-HEMA) shows a characteristic peak of carboxyl group at $1713 \mathrm{~cm}^{-1}$ for the carboxylic group from acrylic acid and the ester group derived from 2-hydroxyethyl methacrylate [44]. The band in question results from the disappearance of the sharp peak at $1635-1633 \mathrm{~cm}^{-1}$ and $818-815 \mathrm{~cm}^{-1}$ (Supplementary fields, Figures S2, S10 and S12), which correspond to the bending vibration of the $\mathrm{C}=\mathrm{C}$ and $\mathrm{C}-\mathrm{H}$ bonds in the vinyl group of the monomer $[20,45]$. The bands found at wavelengths 1417 and $760 \mathrm{~cm}^{-1}$, correspond with the bending and rocking modes of $\mathrm{CH}_{2}$, respectively. These bands are characteristic of acrylic polymers and confirm the successful formation of polyacrylane carbon backbone. The MBA cross-linker in the FTIR spectrum shows the signals characteristic for N-H groups at the wavelength of $3365 \mathrm{~cm}^{-1}$, the peak at the wavelength of $1654 \mathrm{~cm}^{-1}$ shows the $\mathrm{C}=\mathrm{O}$ group, and the peak at $1338 \mathrm{~cm}^{-1}$ confirms the presence of the $\mathrm{C}=\mathrm{C}$ groups.

The superabsorbent polymer abbreviated as PVA/PS-g-P(AA-co-AM) consists of polycarbonate backbone and grafts containing combination of two mers-AA and AMcrosslinked by MBA and from additional free PVA chains penetrating the acryl-starch network. The Oraw spectra of this system are included in the Supplementary Materials (Figures S2-S4, S6, S7 and S9). Figure 4 presents the spectra with the important bands idicated, where a broad band at $3309 \mathrm{~cm}^{-1}$ and it is attributed to the presence of a hydroxyl group that is hydrogen bonded to various degrees. The band at about $2927 \mathrm{~cm}^{-1} \mathrm{can}$ be attributed to the variety of $-\mathrm{CH}_{2}$ stretching vibrations. The bands at the wavelengths 1683 and $1419 \mathrm{~cm}^{-1}$ indicate carboxyl groups. The peaks appearing at $1237 \mathrm{~cm}^{-1}$ in the spectrum can be attributed to the presence of the $\mathrm{C}-\mathrm{O}-\mathrm{C}$ moieties. The band at $1031 \mathrm{~cm}^{-1}$ can be assigned to a $\mathrm{C}-\mathrm{O}$ stretching vibration [46]. The spectrum of the superabsorbent polymer shows the absorption peaks characteristic both of starch and of graft copolymerized acrylic acid and acrylamide. The peak at $1134 \mathrm{~cm}^{-1}$ for poly(vinyl alcohol) attributed to crystalline parts of the polymeric chains was shifted to a lower wavenumber [47]. This shift indicated the formation of hydrogen bonds between poly(vinyl alcohol), and hydrogen bond acceptors in moieties derived from acrylic acid and acrylamide. The $\mathrm{C}-\mathrm{O}-\mathrm{C}$ bond vibration absorption peak at $1147 \mathrm{~cm}^{-1}$ wavelength in starch was significantly reduced due to cross-linking [30]. The spectra presented confirmed the cross-linking of the PVA/SS-g-P(AA-co-AM) polymer.

In the spectrum of PVA/PS-g-P(AA-co-AM-co-AMPS) system peaks corresponding with characteristic groups present in the monomers are observed on polymer spectra with varied intensity, which confirm the incorporation of these monomers in the polymer network. The $\mathrm{NH}_{2}$ stretching band can be found at $3541-3221 \mathrm{~cm}^{-1}$. The band at $1652 \mathrm{~cm}^{-1}$ can be attributed to $\mathrm{C}=\mathrm{O}$ stretching mode, bands at $1539 \mathrm{~cm}^{-1}$, and $1444 \mathrm{~cm}^{-1}$ are characteristic for $\mathrm{NH}_{2}$ groups. Antisymmetric vibrations of $\mathrm{S}-\mathrm{O}$ bonds in $\mathrm{SO}_{2}$ group can be found at $1294 \mathrm{~cm}^{-1}$ and are accompanied by a band at $1031 \mathrm{~cm}^{-1}$ corresponding to symmetrical vibration for $\mathrm{SO}_{2}$ group [40]. The characteristic absorption bands of the sulfonate group at 1156, 1031 and $612 \mathrm{~cm}^{-1}$ can be observed in more details on spectra included in the Supplementary Materials (Figures S1-S4). In the spectra in Figure 4 also show the characteristic bands for aliphatic methylene moieties: $2932,1539,1414 \mathrm{~cm}^{-1}$ corresponding with the asymmetric stretching, asymmetric deformation and symmetrical deformation modes [48]. The presence of these characteristic bands confirms the graft copolymerization of AA, AM and AMPS to starch backbone.

\subsection{Scanning Electron Microscope}

Scanning electron microscopy (SEM) was used to study the morphology of the synthesized samples. Photos a, d, g in Figure 5 show PVA/PS-g-P(AA-co-AM-co-AMPS) at a magnification of $150 \times, 1000 \times, 15,000 \times$, respectively. The recorded samples show dense irregular granules with few cracks typical for polymers comminuted in a grinder. The photos show altered surface morphology compared to the samples of raw starch (smooth, oval pots) [12]. This proves that grafting polymerization significantly alters starch morphology. It is worth noting that most of the superabsorbent polymers reported in the literature have 
pores and spherical cracks, while our samples show linear cracks in seemingly compact grains. This suggests that the obtained systems are micro- and mesoporous. This kind of superabsorbent polymer is more mechanically stable than those having an extensive microporous structure. Microporous SAPs can be used in those industries where high mechanical strength is required. A good application could be agriculture, where polymers are placed deep into the soil and should withstand the associated pressure [49].
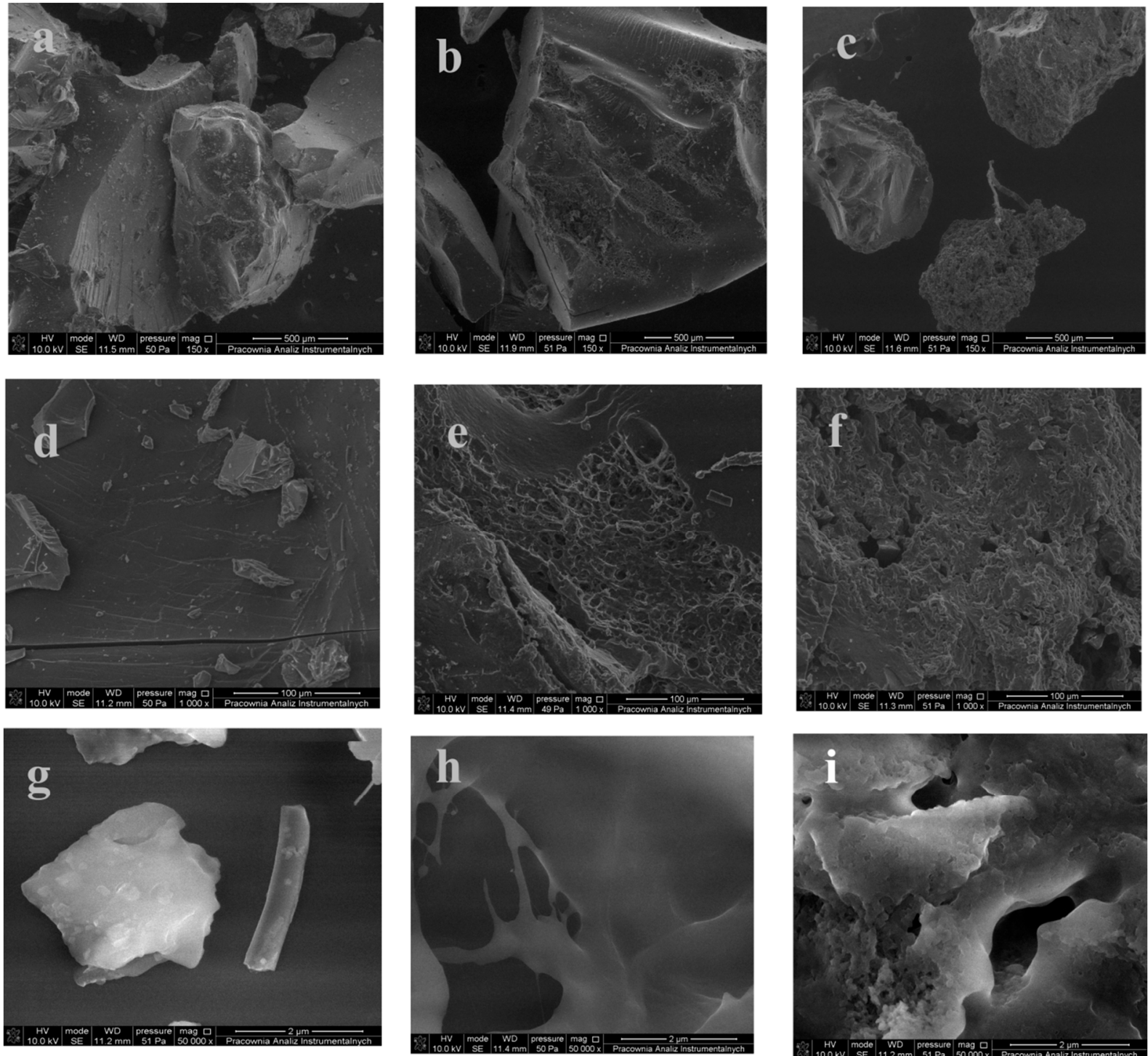

Figure 5. SEM images at $150 \times$ magnification of substances: (a) PVA/PS-g-P(AA-co-AM-co-AMPS), (b) PVA/PS-g-P(AA-coAM), (c) SS-g-P(AA-co-HEMA), 1000× magnification of substances (d) PVA/PS-g-P(AA-co-AM-co-AMPS), (e) PVA/PSg-P(AA-co-AM), (f) SS-g-P(AA-co-HEMA), 50,000 $\times$ magnification of substances (g) PVA/PS-g-P(AA-co-AM-co-AMPS), (h) PVA/PS-g-P(AA-Co-AM), (i) SS-g-P(AA-co-HEMA).

In the case of the PVA/PS-g-P(AA-co-AM) sample (photos b, e, h in Figure 5, enlarged by $150 \times, 1000 \times, 15,000 \times$ respectively), irregular, tightly bound granules have a porous surface with interconnected pores, which can guarantee excellent liquid absorption properties. The pores are culite-shaped with long channels extending into the sample. Presumably, the lattice is more flexible, which allows the liquid to expand more into a larger pore volume. The elongated pores indicate the direction of gas escape during foaming.

The three-dimensional network in the case of the polymer SS-g-P(AA-co-HEMA), shown in Figure $5 c, f, i$ at a magnification of $150 \times, 1000 \times, 15,000 \times$, respectively, is char- 
acterized by the most porous structure. The surface of the superabsorbent polymer is rough with numerous folds and micrograined aggregates. This polymer system, in contrast to that previously discussed, is not a SIPN kind of superabsorbent. The superabsorbent polymer obtained by the modification of starch with AA and HEMA monomers has a very rough structure with microscale interstitial spaces and numerous warts. The surface of the polymer shaped in this way helps to increase the size of the channels, folds and spherical pores, which will facilitate the diffusion and absorption of liquids and increase the speed of moisture penetration into the network, which will consequently ensure excellent swelling properties. All the images shown in Figure 5 are available in their original size in Supplementary Material Figures S38-S46.

By adjusting several factors, pores of a certain size can be produced, including porosity, type and amount of surfactant, amount of solvent, type and amount of inert gas. In the case of superabsorbent polymers, the size and number of pores play a key role in the water absorption and sorption capacity and the rate of liquid absorption by reducing the transport resistance [50]. Three methods are used to create a porous structure: watersoluble porogens [51], foaming [52] and phase separation [53]. In this article, the pores formed are the result of heating in a vacuum.

\subsection{Thermogravimetric Analysis}

Thermal stability is one of the basic features of hygienic materials. This is important not only during use or storage, but also when materials come into contact with the human body. This makes sense especially when a new component with different thermal properties is added to enhance an already used material. Thermogravimetric analysis is the most commonly used technique to study thermal stability. In our work, it was applied to analyze the influence of the chemical composition of the grafts attached to starch on the thermal stability of the starch-based superabsorbent polymers. Thermogravimetric analysis of the superabsorbent polymers and their starting components was performed to assess their degradation profile and thermal stability (Tables 1 and 2 and Figure 6). In Figure 6B-D are shown juxtapositions of the TG plots obtained for pristine material and material after 10 swelling/drying cycles. The presented plots indicate that periodic swelling and drying does not influence thermal stability of the synthesized materials. This aspect is important in the context of their future application as component of hygienic materials, which may be subjected to high temperature treatment (e.g., during sterilization). The components of the individual superabsorbent polymers were also tested for comparative purposes on the basis of the initial decomposition temperature, the percentage of weight loss at various stages of decomposition, and the percentage of residual mass at the maximum decomposition temperature.

Table 1. The mass loss results derived from thermogravimetric analysis (TGA).

\begin{tabular}{|c|c|c|c|}
\hline Sample Code & $\begin{array}{c}\text { TGA } \\
\text { (5 wt } \% \text { Loss) } \\
\left({ }^{\circ} \mathrm{C}\right)\end{array}$ & $\begin{array}{c}\text { TGA } \\
\text { (10 wt } \% \text { Loss) } \\
\left({ }^{\circ} \mathrm{C}\right)\end{array}$ & $\begin{array}{c}\text { TGA } \\
(50 w t \% \text { Loss }) \\
\left({ }^{\circ} \mathrm{C}\right)\end{array}$ \\
\hline SS & 59.2 & 105.4 & 355.9 \\
\hline PS & 70.6 & 280.2 & 315.8 \\
\hline KPS & 295.5 & 472.7 & - \\
\hline MBA & 198.5 & 210.7 & 250.2 \\
\hline AMPS & 190.5 & 193.1 & 243.6 \\
\hline PVA & 251.2 & 260.2 & 297.4 \\
\hline $\mathrm{AM}$ & 107.4 & 119.6 & 282.1 \\
\hline PVA/PS-g-P(AA-co-AM-co-AMPS) & 198.4 & 242.0 & 377.9 \\
\hline SS-g-P(AA-co-HEMA) & 105.6 & 226.7 & 387.2 \\
\hline PVA/PS-g-P(AA-co-AM) & 141.3 & 223.6 & 386.0 \\
\hline
\end{tabular}


Table 2. TG data for monomers and superabsorbent polymers.

\begin{tabular}{|c|c|c|c|c|}
\hline Sample Code & $\begin{array}{l}\text { Temperature of the First } \\
\text { Thermal Event after } \\
\text { Water Evaporation }\left({ }^{\circ} \mathrm{C}\right)\end{array}$ & $\begin{array}{c}\text { Sharp Decomposition } \\
\text { Temperature in the Second } \\
\text { Decomposition Stage }\left({ }^{\circ} \mathrm{C}\right)\end{array}$ & $\begin{array}{c}\text { Maximum } \\
\text { Decomposition } \\
\text { Temperature }\left({ }^{\circ} \mathrm{C}\right)\end{array}$ & $\begin{array}{l}\text { Maximum } \\
\text { Weight Loss } \\
(\%)\end{array}$ \\
\hline SS & 229.5 & 361.8 & 229.5 & 78 \\
\hline PS & 313.9 & - & 313.9 & 55 \\
\hline KPS & 237.5 & 294.3 & 294.3 & 95 \\
\hline MBA & 187.8 & 239.3 & 239.3 & 62 \\
\hline AMPS & 194.0 & 225.9 & 193.4 & 89 \\
\hline PVA & 268.6 & 431.1 & 268.9 & 80 \\
\hline $\mathrm{AM}$ & 152.2 & 243.7 & 152.2 & 68 \\
\hline $\begin{array}{c}\text { PVA/PS-g-P(AA-co-AM- } \\
\text { co-AMPS) }\end{array}$ & 135.9 & 235.6 & 379.4 & 49 \\
\hline SS-g-P(AA-co-HEMA) & 289.5 & 372.2 & 372.2 & 55 \\
\hline PVA/PS-g-P(AA-co-AM) & 213.2 & 241.9 & 356.9 & 60 \\
\hline
\end{tabular}
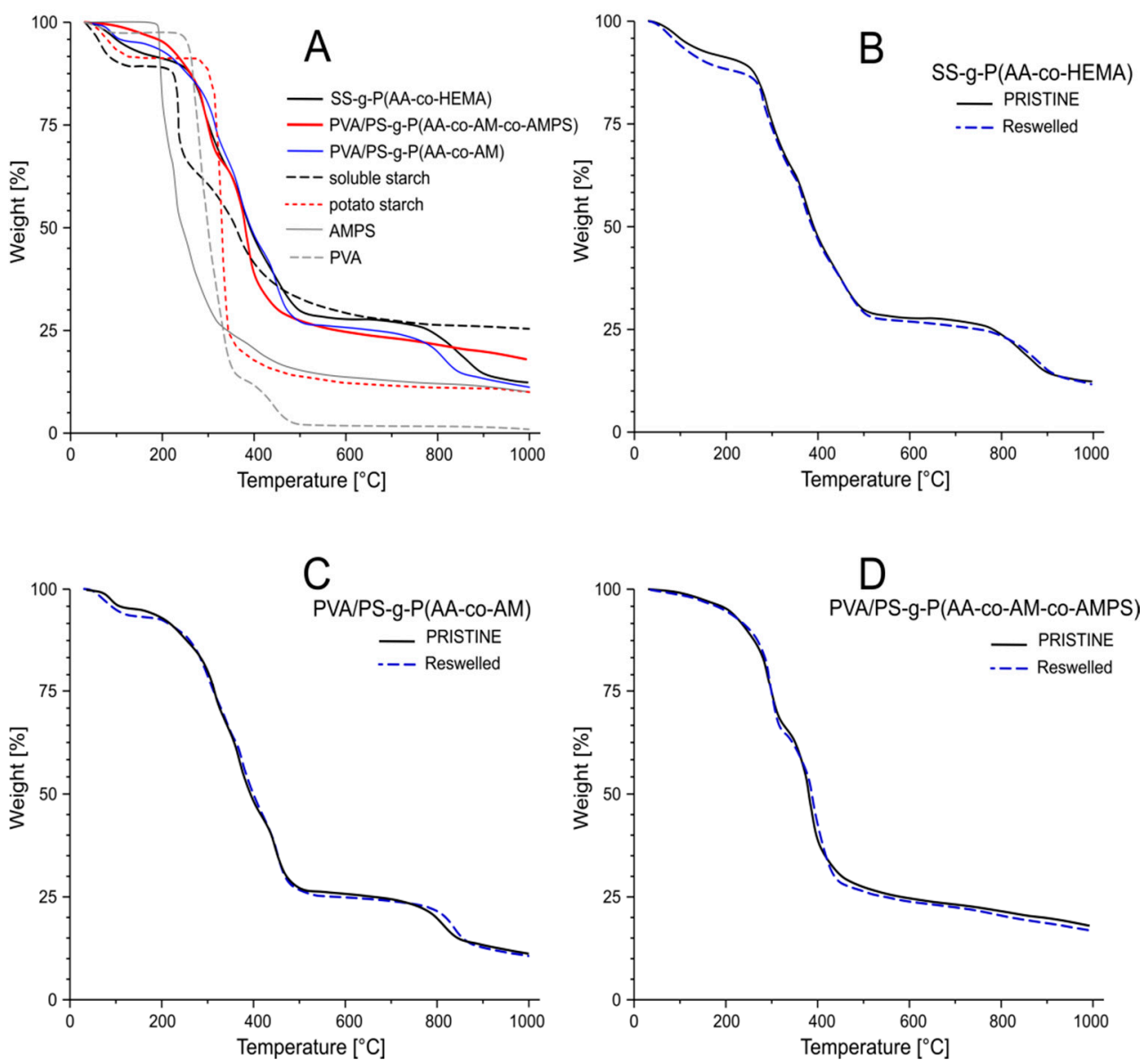

Figure 6. TG curves of studied substances superabsorbent polymers SS-g-P(AA-co-HEMA), PVA/PSg-P(AA-co-AM-co-AMPS), PVA/PS-g-P(AA-co-AM) and selected starting compounds soluble starch, potato starch, AMPS and PVA (A). Comparison of polymer TG curves before swelling and after 10 swelling/drying cycles for SS-g-P(AA-co-HEMA) (B), PVA/PS-g-P(AA-co-AM) (C) and PVA/PSg-P(AA-co-AM-co-AMPS) (D).

Soluble starch (SS) showed a characteristic three-stage thermogram (Supplementary material, Figure S35), where the main weight loss (78\%) occurred in the second stage. On the other hand, the potato starch (PS) shows the maximum decomposition temperature at the second stage, about $313.9^{\circ} \mathrm{C}$. However, the third stage of degradation for the SS was relatively slow; the degradation was almost complete at $361.8^{\circ} \mathrm{C}$. 
Thermogravimetric analysis of SS-g-P(AA-co-HEMA) (Figure 6A, Tables 1 and 2) reveals that the weight loss occurs in five steps. The first stage in the temperature ranges from $45{ }^{\circ} \mathrm{C}$ to $190{ }^{\circ} \mathrm{C}$ and corresponds with $3 \%$ weight loss, which can be explained by a loss of adsorbed remains of residual water and water bound physically (hydrogen bonds). The next stage shows loss of $21.88 \%$ of the weight and span from about $200^{\circ} \mathrm{C}$ to $330^{\circ} \mathrm{C}$. This stage can be attributed to the breaking of $\mathrm{C}-\mathrm{O}-\mathrm{C}$ bonds in the starch main chain and dehydration of saccharide rings $[54,55]$. The third and fourth steps ranging from $335{ }^{\circ} \mathrm{C}$ to $520{ }^{\circ} \mathrm{C}$ characterize the terminal degradation of the various structure of the graft branches composed of the carboxyl groups and the acrylic chains of poly(acrylic acid) and 2-hydroxyethylmethacrylate $[45,55]$. The appearance of these steps indicates successful modification of the structure of the soluble starch chains, due to the grafting of the AA and HEMA chains [56]. The resulting polymer showed less weight loss than pure starch (Table 2). This means that starch grafting increases the thermal stability of the starch cross-linked products to some extent.

The degradation of PVA/PS-g-P(AA-co-AM-co-AMPS) has five steps (Figure $6 \mathrm{~B}$ and Supplementary material, Figure S35). The first decomposition step represents a water evaporation process with a weight loss of $3 \mathrm{wt} \%$ ranges from $35^{\circ} \mathrm{C}$ to $180^{\circ} \mathrm{C}$. The next phase shows a weight loss of $9 \mathrm{wt} \%$ and occurs in temperature range from 190 to $245^{\circ} \mathrm{C}$. This stage is characterized by dehydration of the saccharide rings and breaking the $\mathrm{C}-\mathrm{O}-\mathrm{C}$ bonds in the starch chain [54]. The third stage with a weight loss of $25 \mathrm{wt} \%$ was found in the temperature range from $250{ }^{\circ} \mathrm{C}$ to $330^{\circ} \mathrm{C}$ and may be caused by the oxidation of PVA vinyl backbone to $\mathrm{CO}_{2}$ and might be acceptable evidence for the decomposition of PVA [57]. The next step with the greatest weight loss of $51 \mathrm{wt} \%$ at $379.4{ }^{\circ} \mathrm{C}$ can be attributed to thermal degradation of acrylic graft branches and the removal of the water molecule from adjacent carboxyl groups. This process results in the breaking of the grafted chains and the formation of an anhydride accompanying the destruction of the cross-linked polymer structure [58]. The fifth step occurring at $810.7^{\circ} \mathrm{C}$ with a weight loss $78 \mathrm{wt} \%$ may be the result of the removal of the $\mathrm{SO}_{2}$ molecule from AMPS counterparts of the outer chain attached to the polymer network [6].

The thermal properties of the PVA/PS-g-P(AA-co-AM) superabsorbent were shown in Figure $6 \mathrm{C}$ and assessed by means thermogravimetric analysis (TGA/DTA). The hydrogel thermogram shows the greatest number of decomposition steps, as many as ten. A weight loss of $5 \mathrm{wt} \%$ is attributed to the evaporation of absorbed and bound water (Table 1). The degradation of the polymer in the first five steps showed an approximate weight loss of $16 \mathrm{wt} \%$ over the temperature range from about $30^{\circ} \mathrm{C}$ to $280^{\circ} \mathrm{C}$, which can be attributed to the dehydration and breakdown of the starch particles [59]. The next steps correspond to the degradation of the starch polymer chain, observed in the range of $290{ }^{\circ} \mathrm{C}-500{ }^{\circ} \mathrm{C}$ with a total weight loss of about $66 \mathrm{wt} \%$. A decay above $500{ }^{\circ} \mathrm{C}$ giving $80 \mathrm{wt} \%$ weight loss can be attributed to the degradation of the polymer chains and acrylate cross-linked strains, showing that the thermal stability of the starch copolymers is higher than that of the native starch [12]. The addition of synthetic monomers to the starch improves its thermal stability. This may be attributed to the generation of the new chemical bonds [55].

On the basis of the discussed TGA thermograms, it was found that the temperature at which 5 and $10 \mathrm{wt} \%$ weight loss (Table 1) occurred increased for the obtained superabsorbent polymers as compared to the data for individual monomers. These results show that the thermal stability of the superabsorbent composites, at this point, was lower compared to the single monomers. In the case of $50 \mathrm{wt} \%$, the decomposition temperatures for the superabsorbent polymers are much higher than for the reference materials, which proves a better thermal stability of the samples obtained. This improvement in the thermal stability of the polymers can be attributed to the marked interaction between the monomers concerned and the polymer matrix.

The thermal stability of the superabsorbent polymers can be determined from the initial decomposition temperature ( $\mathrm{T}_{\text {onset }}$ ) given in Table 2 . All the polymers obtained show a lower $\mathrm{T}_{\text {onset }}$ compared to the starting monomers. The results of the TG show that there 
was an increase in the thermal stability of the materials obtained, which confirms the crosslinking of the chains. All the results for the superabsorbent polymers in Table 2 confirm that the obtained materials show better thermal stability than the reference materials, which may increase the use of the resulting products.

\subsection{Swelling Properties of Superabsorbent Polymers}

\subsubsection{Analysis of Water Absorbency}

Superabsorbent polymers used in hygiene products, and especially in disposable diapers, must be characterized by high water retention capacity and high water retention $[60,61]$. These properties increase when the material has the ability to draw water into the polymer matrix, which means a porous structure with many fractures, capillaries and space for the absorbed fluid. To investigate the effect of structural variability on the water absorption efficiency of the produced hydrogels, the amount of water absorbed at equilibrium was studied. The equilibrium swelling $Q_{e q}(g / g)$ of hydrogel was measured based on the temporal evolution of swelling degree $\mathrm{Q}_{\mathrm{t}}(\mathrm{g} / \mathrm{g})$ deionized water $(\mathrm{pH}=6.9 \pm 0.1)$ at $25^{\circ} \mathrm{C}$. Based on the plot $\mathrm{Q}_{\mathrm{t}}=f(\mathrm{t})$ (Figure 7) the mathematical model described by Equation (4) was fitted by means of the least squares technique and the value of retardation time $(\tau)$ was calculated using the transformed form of Equation (3). A similar procedure was applied to interpret the swelling data in other media. The results of the analysis are shown in Table 3.
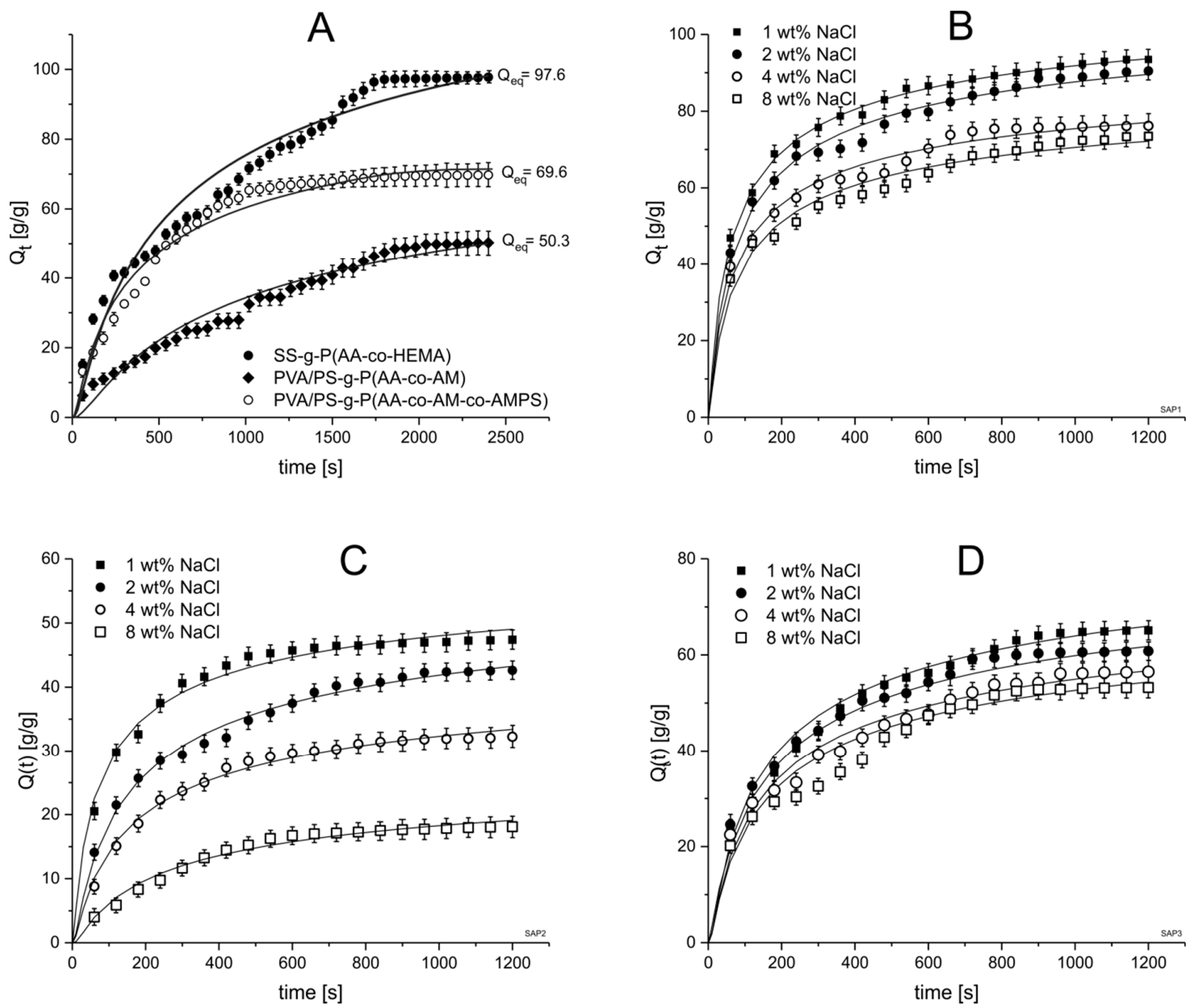

Figure 7. Water absorbency plot of studied polymers in water (A) and in different $\mathrm{NaCl}$ solutions plotted separately for each polymer: SS-g-P(AA-co-HEMA) (B), PVA/PS-g-P(AA-co-AM) (C) and PVA/PS-g-P(AA-co-AM-co-AMPS) (D). 
Table 3. The collection of the results of fitting the experimental data to Equation (4) and values of parameter $\tau$ calculated from Equation (3).

\begin{tabular}{|c|c|c|c|c|c|c|c|}
\hline Solution & $\begin{array}{c}\text { A } \\
{[\mathrm{g} / \mathrm{g}]}\end{array}$ & $\begin{array}{c}b \\
{\left[s^{1 / 2}\right]}\end{array}$ & $\mathbf{R}^{2}$ & FStdE & $\mathbf{F}$ & $\begin{array}{c}\tau \\
{[s]}\end{array}$ & $\begin{array}{c}Q_{\text {eq }} \\
{[\mathrm{g} / \mathrm{g}]}\end{array}$ \\
\hline \multicolumn{8}{|c|}{ SS-g-P(AA-co-HEMA) } \\
\hline Water & 158.86 & 23.58 & 0.965 & 4.86 & 499.5 & 1000.0 & 97.60 \\
\hline $\begin{array}{c}\mathrm{NaCl} 1 \\
\mathrm{wt} \%\end{array}$ & 115.15 & 7.16 & 0.999 & 0.84 & $13,213.1$ & 208.3 & 93.30 \\
\hline $\begin{array}{c}\mathrm{NaCl} 2 \\
\mathrm{wt} \%\end{array}$ & 112.66 & 7.95 & 0.992 & 1.92 & 2400.7 & 222.2 & 90.11 \\
\hline $\begin{array}{c}\mathrm{NaCl} 4 \\
\text { wt } \%\end{array}$ & 96.19 & 7.69 & 0.988 & 2.00 & 1614.1 & 227.3 & 76.07 \\
\hline $\begin{array}{c}\mathrm{NaCl} 8 \\
\text { wt } \%\end{array}$ & 91.39 & 8.20 & 0.984 & 2.21 & 1181.3 & 243.9 & 73.11 \\
\hline \multicolumn{8}{|c|}{ PVA/PS-g-P(AA-co-AM) } \\
\hline Water & 99.78 & 33.78 & 0.970 & 2.57 & 842.1 & 588.2 & 50.30 \\
\hline $\begin{array}{c}\mathrm{NaCl} 1 \\
\text { wt } \%\end{array}$ & 61.36 & 7.78 & 0.990 & 1.20 & 1866.1 & 153.9 & 47.25 \\
\hline $\begin{array}{c}\mathrm{NaCl} 2 \\
\mathrm{wt}^{2} \%\end{array}$ & 60.77 & 11.79 & 0.994 & 0.89 & 3071.1 & 196.1 & 42.48 \\
\hline $\begin{array}{c}\mathrm{NaCl} 4 \\
\text { wt } \%\end{array}$ & 47.17 & 11.98 & 0.993 & 0.73 & 2770.8 & 208.3 & 32.04 \\
\hline $\begin{array}{c}\mathrm{NaCl} 8 \\
\mathrm{wt} \%\end{array}$ & 30.33 & 16.07 & 0.983 & 0.70 & 1128.5 & 227.3 & 17.99 \\
\hline \multicolumn{8}{|c|}{ PVA/PS-g-P(AA-co-AM-co-AMPS) } \\
\hline Water & 107.23 & 18.17 & 0.973 & 3.03 & 756.3 & 333.3 & 69.60 \\
\hline $\begin{array}{c}\mathrm{NaCl} 1 \\
\mathrm{wt}^{2} \%\end{array}$ & 92.00 & 11.50 & 0.996 & 0.93 & 3432.7 & 238.1 & 64.96 \\
\hline $\begin{array}{c}\mathrm{NaCl} 2 \\
\mathrm{wt} \%\end{array}$ & 86.15 & 11.52 & 0.999 & 1.52 & 1665.5 & 249.9 & 60.67 \\
\hline $\begin{array}{c}\mathrm{NaCl} 4 \\
\text { wt } \%\end{array}$ & 79.13 & 11.54 & 0.984 & 1.76 & 1145.4 & 256.4 & 56.34 \\
\hline $\begin{array}{c}\mathrm{NaCl} 8 \\
\text { wt } \%\end{array}$ & 76.27 & 11.73 & 0.999 & 1.10 & 1579.6 & 277.9 & 53.17 \\
\hline
\end{tabular}

The water absorption characteristics of all superabsorbent polymers with different monomer content are shown in Figure 7A. Based on the collected data, it can be observed that the water absorption increases with the immersion time of all samples. The water absorption curves increase quickly during the first few minutes then equilibrate over time and the line flattens out. This type of plot is characteristic for swelling dynamics and indicates a fast uptake of water at the start of the dive, then slowing down near the saturation.

Based on the graph, we can observe that the highest uptake rate and $Q_{\text {eq }}$ are in case of SS-g-P(AA-co-HEMA). This polymer consists of chemically crosslinked graft modified starch without physically interpenetrating additive. The other two polymers have a structure of interpenetrating network of modified starch and PVA. The latter occupies free spaces in a crosslinked starch-acrylane network preventing the system from reaching a high degree of crosslinking. Theoretically, when the crosslinking degree is lower, the water absorbance is higher. In our case, the SAPs composed of interpenetrating networks show significantly lower $Q_{\text {eq }}$ as well as swelling rate at initial stage. This could be explained assuming that the physical interactions between grafted starch chains and PVA are so strong that they prevent easy water uptake.

Comparing the obtained results of the equilibrium swelling for potato starch $\left(Q_{e q}=0.25\right.$ $[\mathrm{g} / \mathrm{g}])$ and soluble starch $\left(\mathrm{Q}_{\mathrm{eq}}=0.90[\mathrm{~g} / \mathrm{g}]\right)$ with the results obtained for the resulting superabsorbent polymers, it can be concluded that, as expected, the starch samples do not 
swell at room temperature and do not retain deionized water. The native starch is insoluble in cold water and most organic solvents, which is especially related to the presence of an insoluble or sparingly soluble amylose fraction (one of which is water). Swelling is an exothermic process during which water molecules are absorbed into the amorphous zone where they are hydrogen bonded to free hydroxyl groups of glucose units in the polymer chains. However, if the aqueous starch suspension is heated above a certain temperature, the starch grains swell spherically and become amorphous. The above thermal transformation is called starch gelatinization and the temperature of this transition is called the gelatinization temperature.

In our previous research it has been confirmed that starch-based superabsorbent polymers can be modified using acrylic acid and this strengthens polymer networks [12]. One can assume that the deionized water absorption mechanism in recent materials is similar to the one described previously. Starch's glucose units contain three hydroxyl groups capable of interacting with water molecules, but are also susceptible to hydrogen bond formation. The second property is responsible for the denser dry state of the polymer but it can also slow down the water absorption process. The graft chains play two important roles in these polymers. Firstly, they substantially increase the interchain distances between amylose and amylopectin chains. The importance of this effect is vital because densely packed polysaccharide chains form strong interchain interactions preventing the system from swelling. Increasing interchain distances facilitates the migration of the solvent through the material. The second aspect concerns the presence of a large number of hydrophilic functional groups, i.e., $-\mathrm{COOH},-\mathrm{NH}_{2},-\mathrm{SO}_{3} \mathrm{H},-\mathrm{CO}\left(\mathrm{NH}_{2}\right)^{-}$. These groups have to be solvated. The ion solvation process requires a large amount of water inside polymer network. Moreover, since some of these ions are fixed to the polymer network, they cannot leave the polymer through leaking. These ions need to be accompanied by relevant counter ions with their solvation spheres. Summing up, ions produced through this dissociation result in an increase in water absorption [62]. Increasing the cross-link density can limit the molecular movement of the SAP chains, which limits the penetration of liquids into the polymer system and thus reduces the deionized water absorption capacity [63].

Figure 7A shows the swelling kinetics of all analyzed superabsorbent polymers in deionized water. The amount of water absorbed by each polymer increased gradually over time until the maximum value was obtained. The swelling increased over time, but after some time it reached its maximum value. This stage is known as equilibrium swelling. Upon contact of the sample with deionized water, the sample swells due to the solvation of ionic groups and hydroxyl groups at the polymer chain. When the hydrogel sample comes into contact with water, the water diffuses into pre-existing or dynamically formed spaces between macromolecular chains and interacts with specific parts of polymer network increasing interchain distances. The water diffusion mechanism in the hydrogel system is significant because it controls the rate of water transfer from environment to superabsorbent where it can be adsorbed. It is important in the hygienic industry, agriculture, biomedicine and environmental protection.

The results obtained for the rate parameter for the analyzed superabsorbent polymers show that deionized water absorption rate decrease in series PVA/PS-g-P(AA-coAM-co-AMPS) (333.33 s), PVA/PS-g-P(AA-co-AM) (544.28 s), and SS-g-P(AA-co-HEMA) (1000.00 s). The data indicate univocally that semi-interpenetrating network hydrogels formed by incorporation of PVA chains to the system reach the saturation level of swelling faster than that composed only of graft modified starch [64]. The swelling kinetics are complicated due to the number of variables that need to be considered. A few of the most important to mention include the complex three-dimensional structure of the polymer network, the specific interaction between the ionophore groups and both the polymer pendant groups and the swelling medium modules, and the conformational freedom of the polymer chains [65]. In deionized water, polymer-water interactions predominate over polymer-polymer interactions, which allows for the swelling. However, the formation of 
polymer water adducts usually requires the breaking down of the initial polymer-polymer adducts. This process has a significant influence on swelling kinetics.

\subsubsection{Effect of Various $\mathrm{pH}$ Solutions on Swelling Behaviors}

An important issue in the swelling of superabsorbent polymers is their sensitivity to the ionic strength and $\mathrm{pH}$. This comes from a large number of ionogenic groups present in the acrylic graft chains. The carboxylic group at low $\mathrm{pH}$ are associated and their degree of dissociation increases with $\mathrm{pH}$. Dissociated ionophere groups attract more water to create solvation spheres, stabilizing the ion charge. This process strongly influences water uptake. Another important aspect is related to ions' interchange between the gel polymer matrix and the surrounding medium, which is closely related to the ionic strength of the latter. In the study, the $\mathrm{pH}$ of the solvent was controlled with a $\mathrm{pH}$ meter by ChemLand, model 7011-01, with conductivity electrode and adjusted with $0.1 \mathrm{M} \mathrm{NaOH}$ and $\mathrm{HCl}$ solutions. All three samples of polymers swelling showed a clear sensitivity to a change in $\mathrm{pH}$, which is demonstrated on Figure 8B.

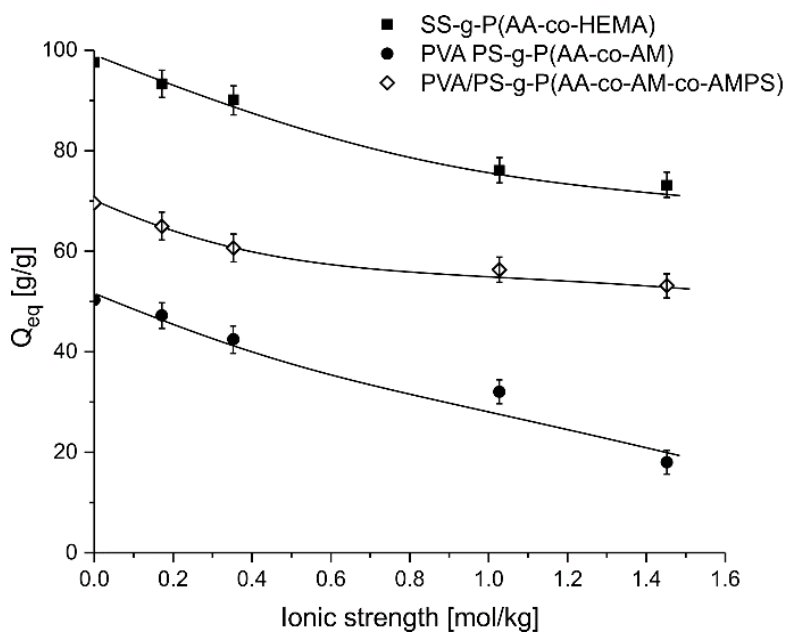

(A)

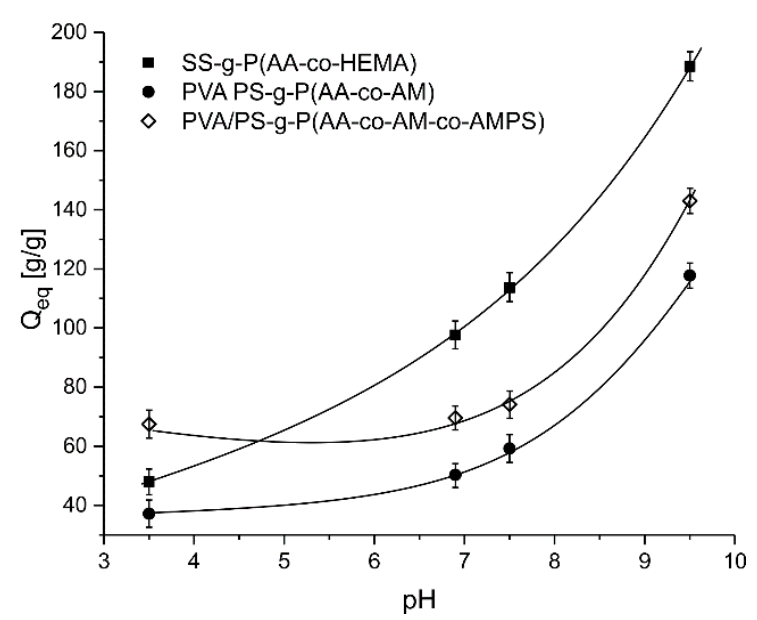

(B)

Figure 8. Dependence of hydrogels swelling on ionic strength (A) and $\mathrm{pH}(\mathbf{B})$.

Based on the obtained results, presented in Figure 8A,B, we can observe the increasing equilibrium swelling with higher $\mathrm{pH}$. Moreover, it is evident that at lower $\mathrm{pH}$ (below 7) the influence is weak, while in the alkalic region $Q_{\text {eq }}$ steeply raises. This can easily be attributed to influence of $\mathrm{pH}$ on the dissociation of ionic groups. When the $\mathrm{pKa}$ for a given ionic group is higher than the $\mathrm{pH}$ of the solution, the group is associated and does not contribute largely in the water uptake process [40]. In all the polymers the carboxylic group are present in large amounts and their attribution is significant at higher $\mathrm{pH}$. However, there are also $-\mathrm{SO}_{3} \mathrm{H}$ groups present in AMPS counterparts of PVA/PS-g-P(AA-co-AM-co-AMPS) and they are responsible for higher water absorption compared to PVA/PS-g-P(AA-co-AM). Additionally, the acidic environment causes the stiffening of the polymer chains and as a result, of the protonation of sulfonic and carboxylic anions and the formation of hydrogen bonds between carboxylic carbonyl oxygen and the amide group of the acrylamide moieties, which causes the superabsorbent to contract. The anion-anion interaction (repulsion) increased the absorption properties (increased space between the chains) and the degree of ionization of the $-\mathrm{COOH}$ and $-\mathrm{SO}_{3} \mathrm{H}$ groups with the increase in the acidity of the solution [66]. The increase in anion density itself improves the absorption properties of the material, which results in an increase in the hydrophilicity of the superabsorbent polymers, facilitating the diffusion of the solution into the molecule [67]. 


\subsubsection{Effects of Saline Solutions on Swelling Behaviors}

When developing materials for potential applications in hygienic products, the absorption of different concentrations of salt solutions is a very important parameter. In this section the superabsorbent polymers' absorbency of $\mathrm{NaCl}_{\mathrm{aq}}$ solutions of $1 \mathrm{wt} \%, 2 \mathrm{wt} \%$, $4 \mathrm{wt} \%$ and $8 \mathrm{wt} \%$ were analyzed. The properties of the external solution, such as charge valence and salt solution concentration, have a great influence on the swelling of superabsorbent polymers [68]. Figure 8A,B show the results of the liquid absorption and it can be seen that the equilibrium absorption of the salt by the superabsorbent polymers in the $\mathrm{NaCl}_{\mathrm{aq}}$ solution clearly decreases with increasing concentration. The shrinkage of the products is largely due to the fact that with an increase in the concentration of the external salt solution, the difference in osmotic pressures decreases, and the influence of the penetrating $\mathrm{Na}^{+}$counterions on the anionic groups $\left(\mathrm{COO}^{-}, \mathrm{SO}_{3}{ }^{-}\right)$weakens the anion-anion repulsion between the carboxylate groups, thus reducing the swelling capacity [69]. The highest absorption values of the $\mathrm{NaCl}_{\mathrm{aq}}$ solution were recorded for SS-g-P(AA-co-HEMA) reaching $\mathrm{Q}_{\text {eq }}$ of 93.3 (see Table 3) in $1 \mathrm{wt} \% \mathrm{NaCl}_{\mathrm{aq}}$ solution. For all three polymers the sorption of the $\mathrm{NaCl}_{\mathrm{aq}}$ solution is lower than the sorption of pure water, and it decreases with the salt concentration. This is clearly seen from the graphs in Figure 7B-D, where the swelling dynamics is plotted for each polymer in every $\mathrm{NaCl}$ concentration. Additionally, in Table 3 the numerical parameters of the swelling curves and the experimental estimation of $Q_{e q}$ are shown.

The research confirms the conclusion that all monovalent cationic forms with the same concentrations have a similar effect on the acrylate-based SAP capacity. The absorption capacity decreased several times (three to four times less) in the presence of salt ions compared to the absorption in deionized water. As already mentioned, the decrease in absorbency could result from a decrease in the osmotic pressure difference (ionic pressure) between the polymeric gel and the external solution, as the concentration of mobile ions between the gel and the aqueous phase decreases [70].

In order to investigate the effect of $\mathrm{NaCl}$ concentration on the swelling kinetics of the superabsorbent polymers in question, the increase in adsorbed mass over time was measured, and the swelling kinetics of the samples were plotted in Figure 7. As with deionized water, there was a sharp increase in sample swelling in the initial few minutes, and over time the line flattened approaching the equilibrium value. The superabsorbent polymers show sensitivity to $\mathrm{NaCl}$ solution concentration, due to the ionic strength influence on the dissociation equilibrium of both the deprotonable $-\mathrm{COOH}$ and protonable $-\mathrm{NH}_{2}$ groups. The influence of ionic strength on the equilibrium swelling is shown in Figure 8A. The presented points correspond to the experimental value, while the lines show only a general trend and do not reflect any reasonable theoretical model. The general trend is the same for all studied absorbents, i.e., the absorbency decreases with the increase in the solution's ionic strength. The highest $Q_{\mathrm{eq}}$ values were found for polymer without additive of interpenetrating PVA (SS-g-P(AA-co-HEMA)). In the case of polymers with additional PVA, the system PVA/PS-g-P(AA-co-AM-co-AMPS) shows better swelling parameters due to presence of $-\mathrm{SO}_{3} \mathrm{H}$ groups.

\section{Conclusions}

Every day, research is carried out in many research centers to create a biodegradable superabsorbent that will meet the requirements of laws, regulations, and the demands of producers as well as consumers for disposable hygiene products. The biggest challenge is to obtain the products' excellent absorption properties, which is not easy when they must also be biodegradable. The presented research is part of a large project whose main goal is to obtain a disposable hygiene product to reduce the amount of plastics ending up in landfill.

By grafting polymerization, two superabsorbent polymers were synthesized based on starch: SS-g-P(AA-co-HEMA), and starch + PVA interpenetrating polymer networks: PVA/PS-g-P(AA-co-AM-co-AMPS), PVA/PS-g-P(AA-co-AM). The polymers were grafted 
using a set of acrylic monomers such as acrylic acid (AA), 2-hydroxyethylmethacrylate (HEMA), poly(vinyl alcohol) (PVA), acrylamide (AM), and 2-acrylamido-2-methylpropane sulfonic acid (AMPS). The reactions were initiated with potassium persulfate and $N, N^{\prime}-$ methylenebisacrylamide was used as a crosslinker. Fourier Transform Infrared Spectroscopy (FTIR) and thermogarvimetric analysis (TA) confirmed the formation of the expected products and the cross-linking of chains. The examination of the morphology of the separated polymer grains using the scanning electron microscope (SEM) method confirmed that the obtained materials had a porous structure, which had a decisive influence on the absorption properties of individual polymers. SS-g-P(AA-co-HEMA) showed the greatest number of channels, spaces between layers and pores. Their positive impact on water uptake was confirmed by the results of swelling for deionized water. The $\mathrm{pH}$ has a significant influence on the swelling capacity; the more alkaline the environment, the higher the liquid absorption rate for all superabsorbent polymers tested. The highest value of $\mathrm{Q}_{\mathrm{eq}}$ at $\mathrm{pH} 9.5$ was found for the sample PVA/PS-g-P(AA-co-AM-co-AMPS) due to presence of sulfonic groups. The swelling capacity of the materials decreased with the increasing concentration of the $\mathrm{Na}^{+}$ions. It can be assumed that the ionic repulsion between the charged groups incorporated into the gel matrix by external $\mathrm{pH}$ modulation is the main driving force responsible for the observed swelling characteristics. Analyzing the deionized water absorption rate parameter, the following series of absorbency was established: SS-g-P(AA-co-HEMA) > PVA/PS-g-P(AA-co-AM-co-AMPS) > PVA/PS-g$\mathrm{P}(\mathrm{AA}-\mathrm{co}-\mathrm{AM})$, and the same absorbency decrease series was preserved in the salt solutions. Efforts to improve the swelling profile of superabsorbent polymers are still underway and we hope that the overall performance in terms of water absorption capacity and aqueous solutions will be improved by the further modification of similar hydrogel systems.

Supplementary Materials: The following are available online at: https:/ /www.mdpi.com/article/10.3390/ ijms22094325/s1, Figure S1: FTIR spectra of poly(vinyl alcohol)/potato starch-g-poly(acrylic acidco-acrylamide-co-2-acrylamido-2-methylpropane sulfonic acid), Figure S2: FTIR spectra of acrylic acid (AA), Figure S3: FTIR spectra of acrylamide (AM), Figure S4: FTIR spectra of potato starch (PS), Figure S5: FTIR spectra of potassium persulfate (KPS), Figure S6: FTIR spectra of $N, N^{\prime}$ methylenebisacrylamide (MBA), Figure S7: FTIR spectra of poly(vinyl alcohol) (PVA), Figure S8: FTIR spectra of 2-acrylamido-2-methylpropane sulfonic acid (AMPS), Figure S9: FTIR spectra of poly(vinyl alcohol)/potato starch-g-poly(acrylic acid-co-acrylamide), Figure S10: FTIR spectra of 2-hydroxyethylmethacrylate (HEMA), Figure S11: FTIR spectra of soluble starch (SS), Figure S12: FTIR spectra of soluble starch-g-poly(acrylic acid-co-2-hydroxyethylmethacrylate), Figure S13: TGA of $N, N^{\prime}$-methylenebisacrylamide (MBA), Figure S14: DTA of $N, N^{\prime}$-methylenebisacrylamide (MBA), Figure S15: TGA of potassium presulfate (KPS), Figure S16: DTA of potassium persulfate (KPS), Figure S17: TGA of potato starch (PS), Figure S18: DTA of potato starch (PS), Figure S19: TGA of soluble starch (SS), Figure S20: DTA of soluble starch (SS), Figure S21: TGA of soluble starch-gpoly(acrylic acid-co-2-hydroxyethylmethacrylate) before swelling, Figure S22: DTA of soluble starchg-poly(acrylic acid-co-2-hydroxyethylmethacrylate) before swelling, Figure S23: TGA of poly(vinyl alcohol)/potato starch-g-poly(acrylic acid-co-acrylamide-co-2-acrylamido-2-methylpropane sulfonic acid) before swelling, Figure S24: DTA of poly(vinyl alcohol)/potato starch-g-poly(acrylic acid-coacrylamide-co-2-acrylamido-2-methylpropane sulfonic acid) before swelling, Figure S25: TGA of poly(vinyl alcohol)/potato starch-g-poly(acrylic acid-co-acrylamide) before swelling, Figure S26: DTA of poly(vinyl alcohol)/potato starch-g-poly(acrylic acid-co-acrylamide) before swelling, Figure S27: TGA of poly(vinyl alcohol) (PVA), Figure S28: DTA of poly(vinyl alcohol) (PVA), Figure S29: TGA of 2-acrylamido-2-methylpropane sulfonic acid, Figure S30: DTA of 2-acrylamido-2-methylpropane sulfonic acid, Figure S31: TGA of poly(vinyl alcohol)/potato starch-g-poly(acrylic acid-co-acrylamideco-2-acrylamido-2-methylpropane sulfonic acid) after swelling, Figure S32: DTA of poly(vinyl alcohol) / potato starch-g-poly(acrylic acid-co-acrylamide-co-2-acrylamido-2-methylpropane sulfonic acid) after swelling, Figure S33: TGA of poly(vinyl alcohol)/potato starch-g-poly(acrylic acid-coacrylamide) after swelling, Figure S34: DTA of poly(vinyl alcohol)/potato starch-g-poly(acrylic acid-co-acrylamide) after swelling, Figure S35: The specific decomposition temperatures read from DTA plots of the polymers. 
Author Contributions: Conceptualization, E.C.; formal analysis, E.C.; visualization, E.C., J.N.; investigation, E.C.; methodology, E.C.; project administration, E.C.; resources, E.C.; supervision, J.N.; validation, J.N.: writing - original draft preparation, E.C.; writing-review and editing, J.N. All authors have read and agreed to the published version of the manuscript.

Funding: The Ministry of Science and Higher Education funded this research, within the implementation of the Ph.D. study of Elżbieta Czarnecka. This work was supported by statutory funds of Nicolaus Copernicus University in Torun, Poland and budget of Plastica Sp. z o.o. in Frydrychowo, Poland.

Institutional Review Board Statement: Not applicable.

Informed Consent Statement: Not applicable.

Data Availability Statement: Not applicable.

Conflicts of Interest: The authors declare that they have no known competing financial interests or personal relationships that could have appeared to influence the work reported in this paper.

\section{References}

1. Laftah, W.A.; Hashim, S.; Ibrahim, A.N. Polymer hydrogels: A review. Polym. Plast. Technol. Eng. 2011, 50, 1475-1486. [CrossRef]

2. Cipriano, B.H.; Banik, S.J.; Sharma, R.; Rumore, D.; Hwang, W.; Briber, R.M.; Raghavan, S.R. Superabsorbent hydrogels that are robust and highly stretchable. Macromolecules 2014, 47, 4445-4452. [CrossRef]

3. Rodrigues, F.H.A.; Spagnol, C.; Pereira, A.G.B.; Martins, A.F.; Fajardo, A.R.; Rubira, A.F.; Muniz, E.C. Superabsorbent hydrogel composites with a focus on hydrogels containing nanofibers or nanowhiskers of cellulose and chitin. J. Appl. Polym. Sci. 2014, 131, 1-13. [CrossRef]

4. Rosiak, J.M.; Yoshii, F. Hydrogels and their medical applications. Nucl. Instrum. Methods Phys. Res. Sect. B Beam Interact. Mater. At. 1999, 151, 56-64. [CrossRef]

5. Sharma, K.; Kumar, V.; Kaith, B.S.; Kumar, V.; Som, S.; Kalia, S.; Swart, H.C. Synthesis, characterization and water retention study of biodegradable Gum ghatti-poly (acrylic acid-aniline) hydrogels. Polym. Degrad. Stab. 2015, 111, 20-31. [CrossRef]

6. Bao, Y.; Ma, J.; Li, N. Synthesis and swelling behaviors of sodium carboxymethyl cellulose-g-poly (AA-co-AM-co-AMPS)/MMT superabsorbent hydrogel. Carbohydr. Polym. 2011, 84, 76-82. [CrossRef]

7. De Oliveira, R.L.; da Silva Barud, H.; De Salvi, D.T.B.; Perotti, G.F.; Ribeiro, S.J.L.; Constantino, V.R.L. Transparent organicinorganic nanocomposites membranes based on carboxymethylcellulose and synthetic clay. Ind. Crop. Prod. 2015, 69, 415-423. [CrossRef]

8. Ma, G.; Ran, F.; Yang, Q.; Feng, E.; Lei, Z. Eco-friendly superabsorbent composite based on sodium alginate and organo-loess with high swelling properties. RSC Adv. 2015, 5, 53819-53828. [CrossRef]

9. Wei, Q. Fast-swelling porous starch-g-poly (acrylic acid) superabsorbents. Iran. Polym. J. 2014, 23, 637-643. [CrossRef]

10. Pathania, D.; Sharma, R.; Kalia, S. Graft copolymerization of acrylic acid onto gelatinized patato starch for removal of metal ions and organic dyes from aqueous system. Adv. Mater. Lett. 2012, 3, 259-264. [CrossRef]

11. Abdel-Halim, E.S.; Al-Deyab, S.S. Preparation of poly (acrylic acid)/starch hydrogel and its application for cadmium ion removal from aqueous solutions. React. Funct. Polym. 2014, 75, 1-8. [CrossRef]

12. Czarnecka, E.; Nowaczyk, J. Semi-Natural Superabsorbents Based on Starch-g-poly (acrylic acid): Modification, Synthesis and Application. Polymers 2020, 12, 1794. [CrossRef]

13. Athawale, V.D.; Lele, V. Graft copolymerization onto starch. II. Grafting of acrylic acid and preparation of it's hydrogels. Carbohydr. Polym. 1998, 35, 21-27. [CrossRef]

14. Lee, J.S.; Kumar, R.N.; Rozman, H.D.; Azemi, B.M.N. Pasting, swelling and solubility properties of UV initiated starch-graft-poly (AA). Food Chem. 2005, 91, 203-211. [CrossRef]

15. Zhang, J.; Wang, L.; Wang, A. Preparation and Swelling Behavior of Fast-Swelling Superabsorbent Hydrogels Based on Starch-gPoly (acrylic acid-co-sodium acrylate). Macromol. Mater. Eng. 2006, 291, 612-620. [CrossRef]

16. Alharbi, K.; Ghoneim, A.; Ebid, A.; El-Hamshary, H.; El-Newehy, M.H. Controlled release of phosphorous fertilizer bound to carboxymethyl starch-g-polyacrylamide and maintaining a hydration level for the plant. Int. J. Biol. Macromol. 2018, 116, 224-231. [CrossRef] [PubMed]

17. Hebeish, A.; Mousa, A.; Ramadan, M.A.; Saleh, A. New starch hybrids via etherification of poly (Acrylamide)-starch copolymers with acrylamide. Egypt. J. Chem. 2013, 56, 255-270. [CrossRef]

18. Li, A.; Liu, R.; Wang, A. Preparation of Starch-Graft-Poly (Acrylamide)/Attapulgite Superabsorbent Composite. J. Appl. Polym. Sci. 2005. [CrossRef]

19. Çelik, M.; Saçak, M. Synthesis and characterization of starch-poly (methyl methacrylate) graft copolymers. J. Appl. Polym. Sci. 2002, 86, 53-57. [CrossRef]

20. Sadeghi, M. Synthesis of starch-g-poly (acrylic acid-co-2-hydroxy ethyl methacrylate) as a potential pH-sensitive hydrogel-baseddrug delivery system. Turk. J. Chem. 2011, 35, 723-733. [CrossRef] 
21. Singh, V.; Tiwari, A.; Pandey, S.; Singh, S.K. Peroxydisulfate initiated synthesis of potato starch-graft-poly(acrylonitrile) under microwave irradiation. Express Polym. Lett. 2007, 1, 51-58. [CrossRef]

22. Kenawy, E.R.; Kamoun, E.A.; Mohy Eldin, M.S.; El-Meligy, M.A. Physically crosslinked poly (vinyl alcohol)-hydroxyethyl starch blend hydrogel membranes: Synthesis and characterization for biomedical applications. Arab. J. Chem. 2014, 7, 372-380. [CrossRef]

23. Zhang, C.; Easteal, A.J. Study of free-radical copolymerization of N-isopropylacrylamide with 2-acrylamido-2-methyl-1propanesulphonic acid. J. Appl. Polym. Sci. 2003, 88, 2563-2569. [CrossRef]

24. Xu, K.; Zhang, W.D.; Yue, Y.M.; Wang, P.X. Swelling behaviors of a three-component copolymer (starch graft sodium acrylate and 2-acrylamido-2-methyl-propanosulfonic acid) synthesized by microwave polymerization. J. Appl. Polym. Sci. 2005, 98, 1050-1054 [CrossRef]

25. Deraman, N.F.; Mohamed, N.R.; Romli, A.Z. Swelling kinetics and characterization of novel superabsorbent polymer composite based on mung bean starch-filled poly (acrylic acid)-graft-waste polystyrene. Int. J. Plast. Technol. 2019, 23, 188-194. [CrossRef]

26. El-Hamshary, H.; Fouda, M.M.G.; Moydeen, M.; El-Newehy, M.H.; Al-Deyab, S.S.; Abdel-Megeed, A. Synthesis and antibacterial of carboxymethyl starch-grafted poly (vinyl imidazole) against some plant pathogens. Int. J. Biol. Macromol. 2015, 72, 1466-1472. [CrossRef] [PubMed]

27. Ismail, H.; Irani, M.; Ahmad, Z. Starch-based hydrogels: Present status and applications. Int. J. Polym. Mater. Polym. Biomater. 2013, 62, 411-420. [CrossRef]

28. Li, X.; Xu, S.; Wang, J.; Chen, X.; Feng, S. Structure and characterization of amphoteric semi-IPN hydrogel based on cationic starch. Carbohydr. Polym. 2009, 75, 688-693. [CrossRef]

29. Miao, X. Synthesis and Characterization of Hydrophobically Modified Derivatives of Polysaccharides; Other [q-bio.OT]; Université de Grenoble: Grenoble, France; Sichuan University: Chengdu, China, 2011.

30. Zhu, B.; Ma, D.; Wang, J.; Zhang, S. Structure and properties of semi-interpenetrating network hydrogel based on starch. Carbohydr. Polym. 2015, 133, 448-455. [CrossRef] [PubMed]

31. Khan, S.; Ullah, A.; Ullah, K.; Rehman, N.U. Insight into hydrogels. Des. Monomers Polym. 2016, 19, 456-478. [CrossRef]

32. Dragan, E.S.; Apopei, D.F. Synthesis and swelling behavior of $\mathrm{pH}$-sensitive semi-interpenetrating polymer network composite hydrogels based on native and modified potatoes starch as potential sorbent for cationic dyes. Chem. Eng. J. 2011, 178, 252-263. [CrossRef]

33. Del Real, A.; Wallander, D.; Maciel, A.; Cedillo, G.; Loza, H. Graft copolymerization of ethyl acrylate onto tamarind kernel powder, and evaluation of its biodegradability. Carbohydr. Polym. 2015, 117, 11-18. [CrossRef]

34. Qin, Q.; Tang, Q.; Li, Q.; He, B.; Chen, H.; Wang, X.; Yang, P. Incorporation of H3PO4 into three-dimensional polyacrylamidegraft-starch hydrogel frameworks for robust high-temperature proton exchange membrane fuel cells. Int. J. Hydrogen Energy 2014, 39, 4447-4458. [CrossRef]

35. Xu, Z.; Fei, Q.; Zhang, X. Synthesis of the starch grafting of superabsorbent and high oil-absorbing resin. J. Environ. Sci. 2013, 25, S97-S100. [CrossRef]

36. Wang, J.; Wei, J. Interpenetrating network hydrogels with high strength and transparency for potential use as external dressings. Mater. Sci. Eng. C 2017, 80, 460-467. [CrossRef] [PubMed]

37. Tang, Q.; Sun, X.; Li, Q.; Wu, J.; Lin, J. Fabrication of a high-strength hydrogel with an interpenetrating network structure. Colloids Surf. A Physicochem. Eng. Asp. 2009, 346, 91-98. [CrossRef]

38. Kaity, S.; Ghosh, A. Comparative bio-safety and in vivo evaluation of native or modified locust bean gum-PVA IPN microspheres. Int. J. Biol. Macromol. 2015, 72, 883-893. [CrossRef]

39. Meng, Y.; Ye, L. Synthesis and swelling property of superabsorbent starch grafted with acrylic acid/2-acrylamido-2-methyl-1propanesulfonic acid. J. Sci. Food Agric. 2017, 97, 3831-3840. [CrossRef]

40. Anirudhan, T.S.; Rejeena, S.R. Poly (acrylic acid-co-acrylamide-co-2-acrylamido-2-methyl-1-propanesulfonic acid)-grafted nanocellulose/poly (vinyl alcohol) composite for the in vitro gastrointestinal release of amoxicillin. J. Appl. Polym. Sci. 2014, 131, 8657-8668. [CrossRef]

41. Abdallah, A.M. The effect of hydrogel particle size on water retention properties and availability under water stress. Int. Soil Water Conserv. Res. 2019, 7, 275-285. [CrossRef]

42. Socrates, G. Infrared and Raman Characteristic Group Frequencies: Tables and Charts by Socrates, George: Very Good Spiral-Bound (2004) I WeBuyBooks; John Wiley \& Sons Inc.: Hoboken, NJ, USA, 2004; ISBN 0470093072.

43. Dankar, I.; Haddarah, A.; Omar, F.E.L.; Pujolà, M.; Sepulcre, F. Characterization of food additive-potato starch complexes by FTIR and X-ray diffraction. Food Chem. 2018, 260, 7-12. [CrossRef]

44. Sadeghi, M.; Hosseinzadeh, H. Studies on graft copolymerization of 2-hydroxyethylmethacrylate onto kappacarrageenan initiated by ceric ammonium nitrate. J. Chil. Chem. Soc. 2010, 55, 497-502. [CrossRef]

45. Figueiredo, A.G.P.R.; Figueiredo, A.R.P.; Alonso-varona, A.; Fernandes, S.C.M.; Palomares, T.; Rubio-azpeitia, E.; Barrostimmons, A.; Silvestre, A.J.D.; Neto, C.P.; Freire, C.S.R. Biocompatible Bacterial Cellulose-Poly (2-hydroxyethyl methacrylate) Nanocomposite Films. Biomed. Res. Int. 2013, 2013, 698141. [CrossRef] [PubMed]

46. Bhattacharya, S.S.; Mishra, A.; Pal, D.; Ghosh, A.K.; Ghosh, A.; Banerjee, S.; Sen, K.K. Synthesis and Characterization of Poly (acrylic acid)/Poly (vinyl alcohol)-xanthan Gum Interpenetrating Network (IPN) Superabsorbent Polymeric Composites. Polym. Plast. Technol. Eng. 2012, 51, 878-884. [CrossRef] 
47. Dai, H.; Zhang, Y.; Ma, L.; Zhang, H.; Huang, H. Synthesis and response of pineapple peel carboxymethyl cellulose-g-poly (acrylic acid-co-acrylamide)/graphene oxide hydrogels Synthesis and response of pineapple peel carboxymethyl cellulose-g-poly (acrylic acid-co-acrylamide)/graphene oxide hydroge. Carbohydr. Polym. 2019, 215, 366-376. [CrossRef]

48. Limparyoon, N.; Seetapan, N.; Kiatkamjornwong, S. Acrylamide/2-acrylamido-2-methylpropane sulfonic acid and associated sodium salt superabsorbent copolymer nanocomposites with mica as fi re retardants. Polym. Degrad. Stab. 2011, 96, 1054-1063. [CrossRef]

49. Omidian, H.; Rocca, J.G.; Park, K. Advances in superporous hydrogels. J. Control. Release 2005, 102, 3-12. [CrossRef]

50. Chen, J.; Park, K. Synthesis of fast-swelling, superporous sucrose hydrogels. Carbohydr. Polym. 2000, 41, 259-268. [CrossRef]

51. Badiger, M.V.; McNeill, M.E.; Graham, N.B. Porogens in the preparation of microporous hydrogels based on poly (ethylene oxides). Biomaterials 1993, 14, 1059-1063. [CrossRef]

52. Pourjavadi, A.; Kurdtabar, M.; Ghasemzadeh, H. Salt- and pH-resisting collagen-based highly porous hydrogel. Polym. J. 2008, 40, 94-103. [CrossRef]

53. Gotoh, T.; Nakatani, Y.; Sakohara, S. Novel synthesis of thermosensitive porous hydrogels. J. Appl. Polym. Sci. 1998, 69, 895-906. [CrossRef]

54. Yang, F.; Li, G.; He, Y.G.; Ren, F.X.; Wang, G. Xiang Synthesis, characterization, and applied properties of carboxymethyl cellulose and polyacrylamide graft copolymer. Carbohydr. Polym. 2009, 78, 95-99. [CrossRef]

55. Hua, S.; Wang, A. Synthesis, characterization and swelling behaviors of sodium alginate-g-poly (acrylic acid)/sodium humate superabsorbent. Carbohydr. Polym. 2009, 75, 79-84. [CrossRef]

56. Sadeghi, M.; Yarahmadi, M. Synthesis and characterization of superabsorbent hydrogel based on chitosan-g-poly (acrylic acid-coacrylonitrile). Afr. J. Biotechnol. 2011, 10, 12265-12275. [CrossRef]

57. Liu, J.; Li, Q.; Su, Y.; Yue, Q.; Gao, B.; Wang, R. Synthesis of wheat straw cellulose-g-poly (potassium acrylate)/PVA semi-IPNs superabsorbent resin. Carbohydr. Polym. 2013, 94, 539-546. [CrossRef]

58. Huang, Y.; Lu, J.; Xiao, C. Thermal and mechanical properties of cationic guar gum/poly (acrylic acid) hydrogel membranes. Polym. Degrad. Stab. 2007, 92, 1072-1081. [CrossRef]

59. Qiao, D.; Liu, H.; Yu, L.; Bao, X.; Simon, G.P.; Petinakis, E.; Chen, L. Preparation and characterization of slow-release fertilizer encapsulated by starch-based superabsorbent polymer. Carbohydr. Polym. 2016, 147, 146-154. [CrossRef]

60. Chem, T.J. Swelling Behavior of Acrylamide-2-Hydroxyethyl. Turk. J. Chem. 2000, 24, 147-156.

61. Bajpai, S.K. Superabsorbent hydrogels for removal of divalent toxic ions. Part I: Synthesis and swelling characterization. React. Funct. Polym. 2005, 62, 271-283. [CrossRef]

62. Xie, H. Study on the Preparation of Superabsorbent Composite of Chitosan-g-poly (Acrylic Acid)/Kaolin by In-situ Polymerization. Int. J. Chem. 2011, 3, 69-74. [CrossRef]

63. Ismail, H.; Irani, M.; Ahmad, Z. Utilization of Waste Polystyrene and Starch for Superabsorbent Composite Preparation. J. Appl. Polym. Sci. 2013, 127, 4195-4202. [CrossRef]

64. Zhang, J.; Bhat, R.; Jandt, K.D. Temperature-sensitive PVA/PNIPAAm semi-IPN hydrogels with enhanced responsive properties. Acta Biomater. 2009, 5, 488-497. [CrossRef] [PubMed]

65. Gharekhani, H.; Olad, A.; Mirmohseni, A.; Bybordi, A. Superabsorbent hydrogel made of NaAlg-g-poly (AA-co-AAm) and rice husk ash: Synthesis, characterization, and swelling kinetic studies. Carbohydr. Polym. 2017, 168, 1-13. [CrossRef] [PubMed]

66. Olad, A.; Doustdar, F.; Gharekhani, H. Starch-based semi-IPN hydrogel nanocomposite integrated with clinoptilolite: Preparation and swelling kinetic study. Carbohydr. Polym. 2018, 200, 516-528. [CrossRef] [PubMed]

67. Mandal, B.; Kumar, S. Synthesis of interpenetrating network hydrogel from poly (acrylic acid-co-hydroxyethyl methacrylate) and sodium alginate: Modeling and kinetics study for removal of synthetic dyes from water. Carbohydr. Polym. 2013, 98, 257-269. [CrossRef] [PubMed]

68. Mohana Raju, K.; Padmanabha Raju, M.; Murali Mohan, Y. Synthesis of superabsorbent copolymers as water manageable materials. Polym. Int. 2003, 52, 768-772. [CrossRef]

69. Spagnol, C.; Rodrigues, F.H.A.; Neto, A.G.V.C.; Pereira, A.G.B.; Fajardo, A.R.; Radovanovic, E.; Rubira, A.F.; Muniz, E.C. Nanocomposites based on poly(acrylamide-co-acrylate) and cellulose nanowhiskers. Eur. Polym. J. 2012, 48, 454-463. [CrossRef]

70. Gils, P.S.; Ray, D.; Mohanta, G.P.; Manavalan, R.; Sahoo, P.K. Designing of new acrylic based macroporous superabsorbent polymer hydrogel and its suitability for drug delivery. Int. J. Pharm. Pharm. Sci. 2009, 1, 43-54. 